\title{
Un basurero romano en Madrid
}

\author{
Carmen Guiral Pelegrín*
}

\section{RESUMEN}

Basurero de época romana hallado en el solar del Colegio Mayor $N^{z}$ Sra. de Africa. Los materiales se depositaron en un mismo momento cronológico y constituyen un importante lote de cerámicas de época romana: terra sigillata hispánica, terra sigillata hispánica avellana, cerámica de paredes finas, cerámica pintada de tradición indigena, cerámica vidriada, cerámica común de mesa y de cocina, pondera y material de construcción; además se hallaron diversos restos metálicos y una aguja de hueso. El estudio nos proporciona una cronología de finales del s. I y mediados del s. II.

Aunque el basurero es el único resto romano hallado en el citado solar, no constituye un elemento aislado, ya que

a comienzos del siglo se encontró en el cercano Pte. de los Franceses un ara funeraria, asociada a cerámicas y monedas que sin duda era parte de

\section{ABSTRACT}

A roman rubbish dump was founded through the archaeological excavation at the Colegio Mayor $N^{a}$ Sra. de Africa. The materials were placed in the site at the same time and they are an important assemblage of roman pottery: T.S.H., T.S.H. avellana, Thin-walled pottery, painted pottery, glaced pottery, kitchen and table common pottery, pondera and building material; moreover it was founded several metal remains and one bone needle. The complete study offers a chronological frame work between the end of I century and the middle of Ilnd century.

Although the rubbish dump is the only one roman remain founded in the mentioned excavation, it is not an isolated factor, since at the beginings of this century, it was founded a funeral altar stone, near

* Departamento de Prehistoria e Historia Antigua. UNED. 
una necrópolis perteneciente a una villa, uno de cuyos basureros se analiza en este artículo.

A la importancia de sumar un nuevo hallazgo en Madrid, se añade el hecho de ser uno de los pocos vestigios romanos excavados recientemente en

la capital y que además aporta interesantes datos cronológicos y económicos para el análisis de la presencia romana en la zona.
Pte. de los Franceses, asociated to pottery and coins that, probably, were part of the necropolis from a next villa.

This finding is un importat discovery, because it is one of the few roman remains excavated recently at Madrid and also it provides interesting chronological and economical data for the comprehesion of roman traces in the area.

Las excavaciones se llevaron a cabo en el interior de la Ciudad Universitaria, concretamente en el solar ubicado en el cruce de las calles Obispo Trejo y Senda del Rey, con motivo de las obras realizadas para la remodelación del Colegio Mayor $\mathrm{N}^{2}$ Sra. de Africa. Los trabajos arqueológicos estuvieron a cargo de la empresa Archeo System S.L., Soluciones Arqueológicas y fueron dirigidos por Ana $M^{a}$. Muñoz Amilibia, catedrática de Prehistoria de la UNED y Don José Sánchez Meseguer, profesor de la Universidad Autónoma, encargándose directamente de la excavación Helena Romero Salas y Ana $\mathrm{M}^{\mathrm{a}}$ Garcés Tarragona 1.

Los hallazgos inmuebles registrados en el espacioso solar de casi $2000 \mathrm{~m}^{2}$ se reducen casi exclusivamente a restos constructivos de fines del siglo pasado, como son las estructuras de ladrillo y mortero, pertenecientes a las canalizaciones de las huertas y viveros que se situaban en la zona desde 1856 y que corresponden al denominado estrato IV, cuya cronología oscila entre la citada fecha y los inicios de la Guerra Civil.

Todos los materiales recogidos son contemporáneos y pertenecen a los escombros y rellenos vertidos para remozar una zona de la ciudad, cuyo paisaje se había transformado considerablemente como consecuencia de los acontecimientos bélicos de la Guerra Civil, de la que se han documentado trincheras y nidos de ametralladora.

1 Todos los datos relativos a la excavación expuestos en este artículo han sido extraídos de la Memoria de excavaciones en cuya redacción participamos aportando el estudio del basurero. Agradecemos a los Directores de la Excavación la posibilidad de publicar datos inéditos relacionados con la metodología de trabajo y con los resultados obtenidos en la totalidad de la superficie excavada. Asimismo nuestra gratitud por las facilidades prestadas en el estudio de los materiales de época romana.

También nuestro agradecimiento a los Drs. M. Beltrán Llofis, C. Aguapod Otal, J.A. Minguez Morales y C. SAEnz PRECIAdo por las sugerencias aportadas en el estudio de las distintas familias cerámicas. 


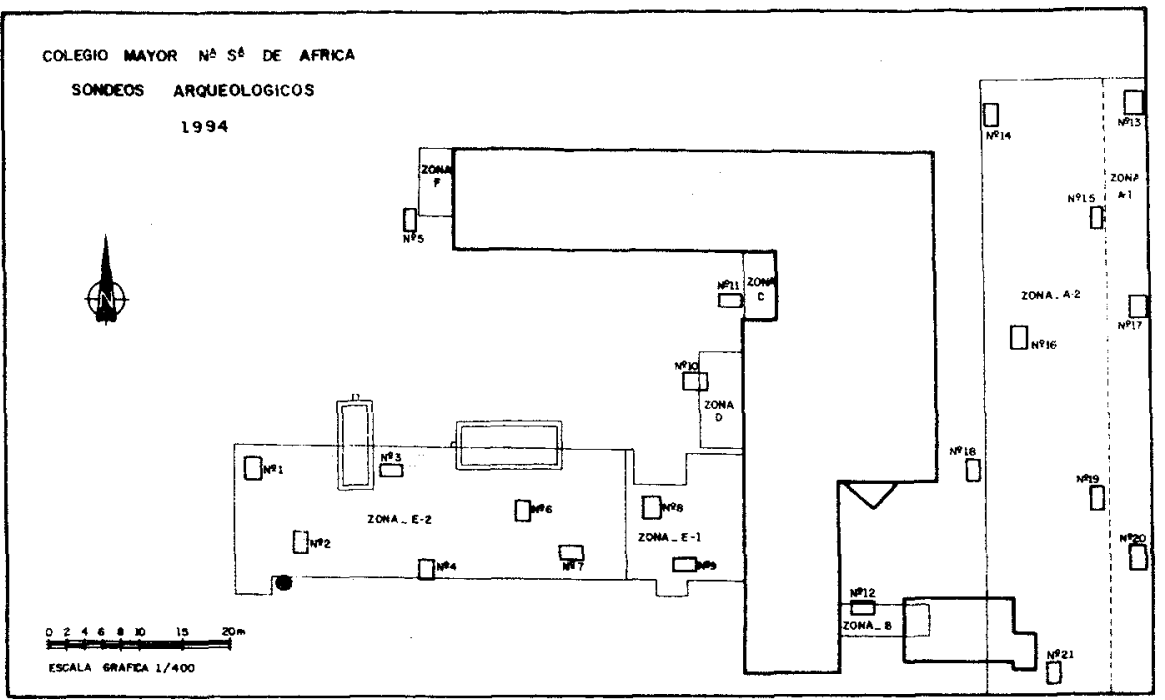

Figura 1. Colegio Mayor: $N^{a}$ Sra. de África. Sondeos arqueológicos.

De estas características generales válidas para la práctica totalidad del solar hay que hacer una excepción, la localización de un basurero de época romana que ha suministrado un importante lote de material cerámico de gran importancia para estudiar la presencia romana en el núcleo urbano de Madrid.

\section{EL BASURERO ROMANO. CARACTERÍSTICAS GENERALES}

El hallazgo se llevó a cabo durante la excavación del denominado corte 22 que presenta unas dimensiones de $3,40 \mathrm{~m}$. de longitud y 2,30 m. de anchura y se situa en la zona meridional del solar. La estructura de época romana puede describirse como una fosa de planta ovalada y perfil de forma triangular de 1'37 m. de altura (lámina I).

Arqueológicamente corresponde al denominado estrato $\mathrm{V}$, concentrado únicamente en el basurero y que solamente estaba alterado en la superficie por una conducción de época contemporánea. Este depósito se excava en el estrato IV compuesto por materiales de sedimentación natural (tierra arcillo-limosa) dispuestos en varios niveles correspondientes a distintas inundaciones.

La citada fosa está colmatada por sucesivas capas de basura, cenizas, tierra de filtraciones, etc., todas ellas mezcladas con material arqueológico abundante y variado desde un punto de vista morfológico. 


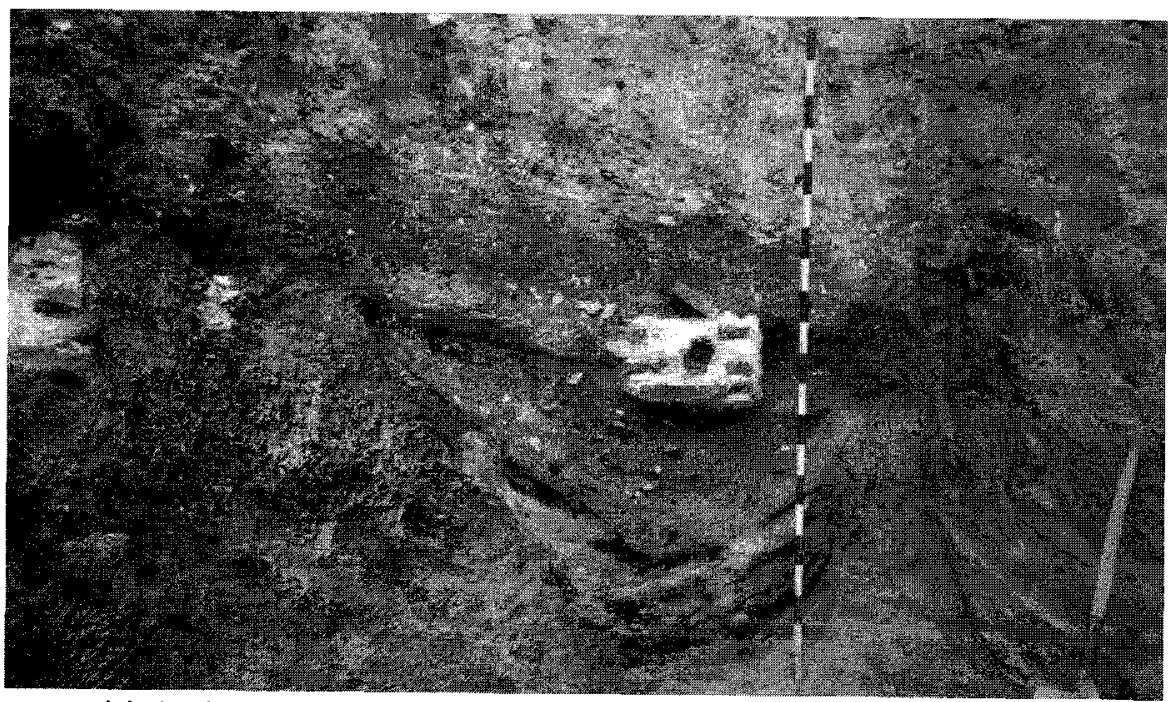

Lámina I. Corte 22, con detalle de la sección del basurero. (Foto A. Muñoz.)

La excavación se realizó en 10 capas sucesivas, las dos primeras pertenecen a toda la superficie del corte, denominado 22 en el conjunto de la excavación, y el resto únicamente a la fosa (figura 2).

La capa 1 estaba compuesta por arena arcillosa de color marrón en la que aparecieron mezcladas cerámicas contemporáneas y romanas (Inv. no 2200).

La capa 2 presenta idéntico tipo de tierras y está atravesada por una canalización; en esta capa se aprecia claramente la estructura de la fosa que se situa bajo la cañería y cuyas dimensiones son de 2'10 m. de longjtud por 1'20 m. de anchura. La mezcla de material es idéntica a la de la capa anterior (Inv. $n^{0} 2201$ ).

En el inicio de la excavación de la capa 3 la tierra es de color gris muy oscuro y está mezclada con carbones y cenizas (Inv. n²202). Los materiales son ya de época romana e incluyen cerámica, metal y restos de fauna, al igual que sucede en la capa 4 (Inv. no 2203), 5 (Inv. no 2204) y 6 (Inv. no 2205).

En la capa 7, los carbones disminuyen considerablemente si bien no se aprecian diferencias en cuanto a los restos materiales (Inv. $n^{\circ} 2206$ ). La capa 8 nos ofrece un volumen de material considerablemente superior a los anteriores (Inv. $\mathrm{n}^{\mathrm{0}} 2209$ ) y en las tierras comienzan a desaparecer los carbones, hecho mucho más evidente en la siguiente capa, en la que ya solamente se constata la tierra amarillenta con algunos restos de carbón y escasísimos restos de material (Inv. $n^{\circ} 2215$ ). 


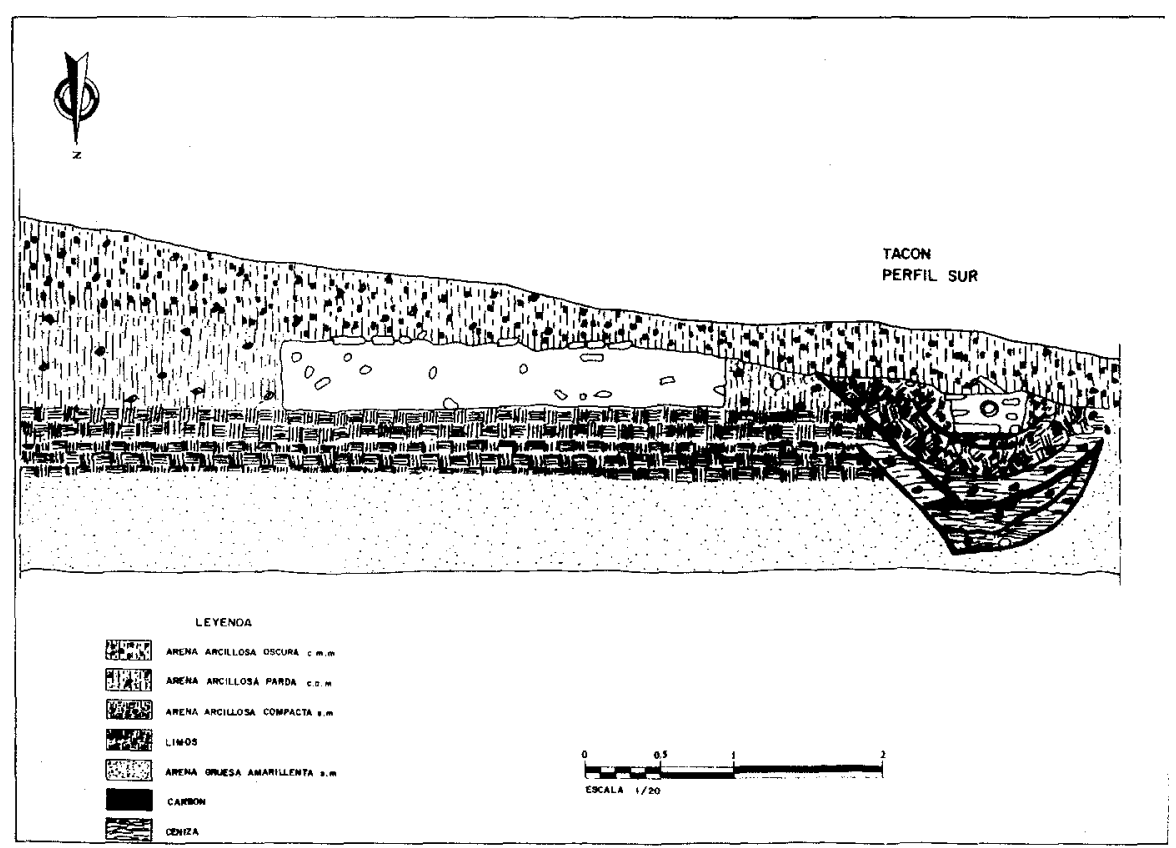

Figura 2. Estratigrafía del Corte 22, según Sánchez Meseguer.

\section{COMENTARIO ESTRATIGRÁFICO}

Como ya hemos expuesto, la excavación del basurero se llevó a cabo en diferentes capas y así se ha realizado el inventario de los restos cerámicos hallados. El primer análisis de los mismos, nos permite concluir que idénticos tipos cerámicos aparecen en los distintos estratos e incluso algunos fragmentos pertenecientes a la misma pieza se encuentran en niveles alejados, como es del plato hallado prácticamente completo en 2210 , al que pertenece un pequeño fragmento del primer nivel excavado.

De todo ello podemos concluir que el depósito se realizó en un único momento, hecho que reviste una importancia esencial para su estudio cronológico.

\section{ESTUDIO DE LOS MATERIALES}

Una vez comprobado que los materiales se depositaron en la fosa en el mismo momento y, por lo tanto, no es necesario un análisis detallado de 
cada uno de los niveles, se ha optado por realizar el estudio atendiendo a las familias cerámicas.

\subsection{Terra Sigillata hispánica}

Es el tipo cerámico que aparece con mayor profusión en el basurero. Sin embargo hay que advertir el pequeño tamaño $y$, en algunos casos, deterioro de la mayoría de los fragmentos, que impide su clasificación tipológica.

\subsubsection{Pastas}

Atendiendo a las pastas y barnices podemos clasificar el conjunto en cuatro grupos diferentes:

Pasta 1. Compacta, decantada y poco porosa. De color rojo ladrillo. Desgrasante fino, compuesto por cuarzos y micas. Barniz rojo anaranjado.

Pasta 2. Es la típicamente hispana. Más anaranjada que la anterior y también más arenosa. El desgrasante es similar. Barniz rojo anaranjado. Es la más abundante.

Pasta 3. Pasta anaranjada, muy arenosa. Barniz muy ligero.

Pasta 4. Pasta de color ocre claro con desgrasante grueso en el que se observan puntos de color oscuro. El barniz es de color rojo vinoso.

\subsubsection{Talleres}

Las tres primeros grupos de pastas corresponden a la producción de Tritium Magallum (Tricio, La Rioja), con una mayor calidad la pasta 1, que también se corresponde con las mejores piezas, como veremos posteriormente. Por lo que se refiere a la pasta 3 , solamente aparece en tres pequeños fragmentos de la capa 2200 , lo que unido a su baja calidad, podría llevarnos a considerar su pertenenecia a un momento ligeramente posterior.

Por lo que se refiere al grupo 4 que aparece únicamente en nueve fragmentos, no procede de Tricio ni de los talleres hispanos más conocidos, por lo que cabría pensar en la posibilidad de que proviniera de un taller de ubicación incierta en el Valle del Tajo. 


\subsubsection{Sellos y grafitos}

En el fondo de dos recipientes aparecen restos de sigilla, con el nombre de la officina donde se fabricaron:

- En el fondo de la copa Drag. 35 quedan restos del cartucho en el que sólo puede apreciarse O. [- - ], abreviatura de officina. (2201.1, fig. 3.2).

- En este caso únicamente se conserva el fondo de la pieza y el escaso relieve del sello, impide una lectura completa. Puede leerse C [-] OF (2203.6).

Los grafitos, que corresponden generalmente a los nombres de los propietarios de los recipientes, aparecen en la superficie exterior de los mismos:

- En la pared de la copa Drag. 35 anteriormente citada (2201.1, fig. 3.2).

- En el fondo de la posible pátera (2214.3/2215.1, fig. 4.7).

\subsubsection{Formas} das.

En este apartado hay que distinguir las formas lisas de las decora-

\subsubsection{Lisas}

De entre todos los fragmentos, únicamente se han podido distinguir con claridad cuatro formas lisas, muy características de la producción hispánica de época altoimperial:

- Drag. 15/17. Contamos con dos fragmentos de la moldura interior de la carena (2203.7 y 2205.1) y con un fragmento de borde (2207.1/2209.1, fig. 3.1) que nos permite incluir esa pieza en el grupo III caracterizado por presentar el borde ligeramente curvado ${ }^{2}$. Este plato de borde más o menos oblicuo, fondo plano con pie de sección triangular, es la forma más frecuente de la producción hispánica, característica de la segunda mitad del s. I.

\footnotetext{
2 MAYET, F., Les céramiques sigillées hispaniques. Contribution à l'histoire économique de la Peninsule Ibérique sous l'Empire Romain, París 1984, p. 71, lám. LIX.
} 

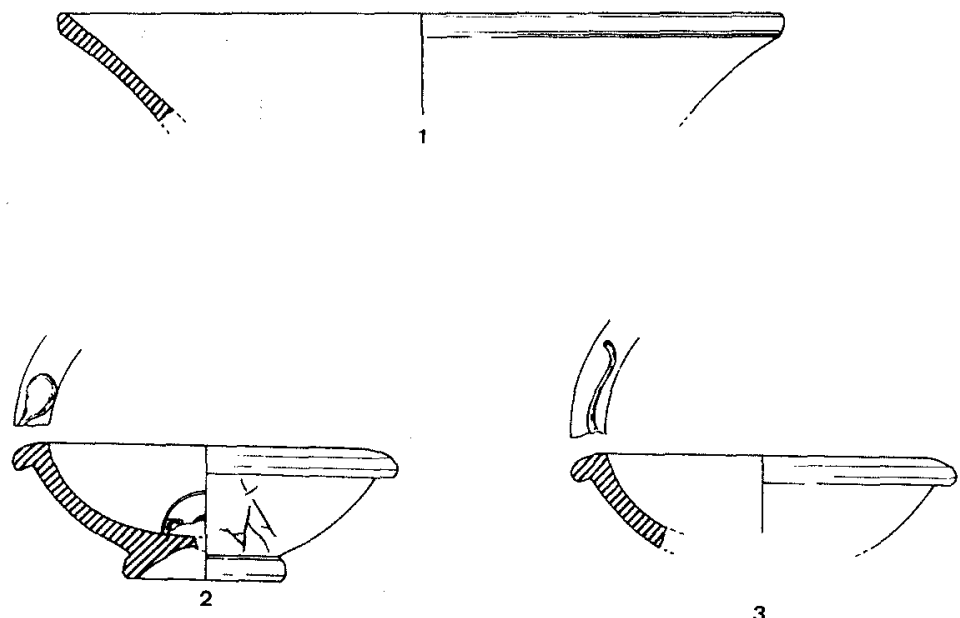

3

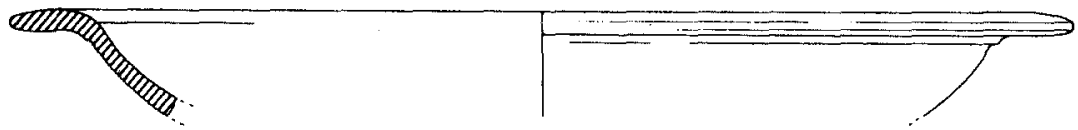

4
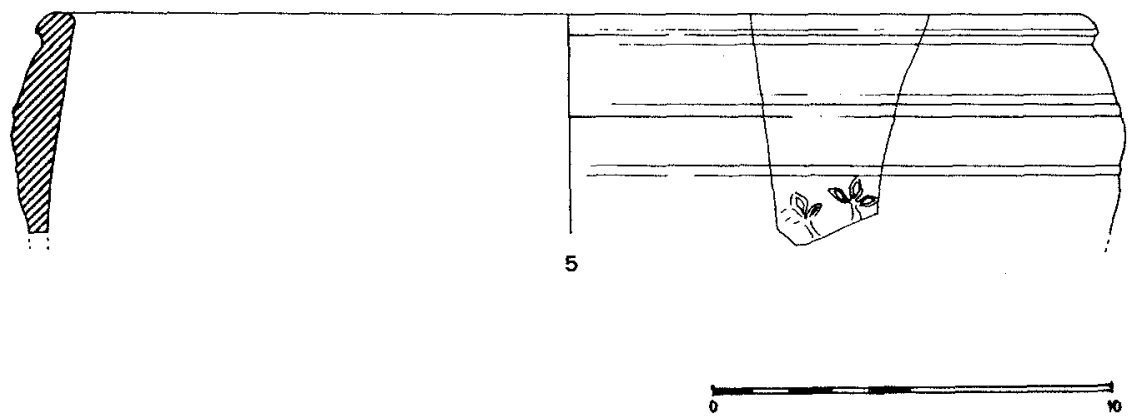

Figura 3. Terra Sigillata Hispánica. 
- Drag. 27. Contamos con dos ejemplares de la pared (2203.3 y 2203.11) con su doble curva que, en muchos casos, constituye dos cuartos de círculo. La forma comienza su producción a mediados del siglo I.

- Drag. 35. Se han hallado dos fragmentos (2201.1/ 2204.2, fig. 3.23) pertenecientes a la misma copa, de panza semiesférica, borde doblado hacia el exterior y decorado con hojas de agua a la barbotina. En la clasificación de Mayet pertenece al grupo I, que incluye las copas más pequeñas, con un diámetro de $8 \mathrm{~cm}$., y una altura menor a $4 \mathrm{~cm}$. Cronológicamente su producción se situa entre la segunda mitad del s I y la primera del s. II d.C.

- Drag 36. Contamos con restos de dos piezas diferentes (2201.2/2204.1, fig. 3.4 y 2214.1-2). Su forma es similar a la Drag. 35, si bien presenta un diámetro mucho mayor y menor altura, que lo asemeja a un plato. El ejemplar 2201.2/2204.1 (fig. 3.4) se incluye dentro de los más grandes de la producción de Tricio $^{3}$. Su cronología es la misma que la de la copa Drag. 35.

\subsubsection{Decoradas}

Se han hallado numerosos fragmentos decorados, pero la mayoría de ellos son de tamaño muy pequeño, por lo que es imposible adscribirlos a una forma concreta y solamente lo esteriotipado de los motivos decorativos de la T.S.H. permite su descripción en el inventario. Los fragmentos que pueden identificarse morfológicamente pertenecen en su mayoría a la forma Drag. 37 y sólo uno a la Drag. 30.

- Drag. 30. El pequeño fragmento (2214.12) que atribuímos a esta forma por la pequeña moldura de cuarto de círculo situada en el interior, en la zona de unión entre la pared y el fondo, moldura que es característica de las piezas hispánicas. Esta forma comienza su producción a mediados del s. I y finaliza su producción con el siglo, ya que carece de la decoración de círculos característica del s. II.

- Drag. 37. Es la forma más abundante de la T.S.H. decorada. Presenta un cuerpo semiesférico, con borde vertical o ligeramente curvado hacia el interior. Existen dos variedades y ambas están presentes en nuestra excavación:

3 Mayet, F., op. cit., lám. CXX.177-179. 

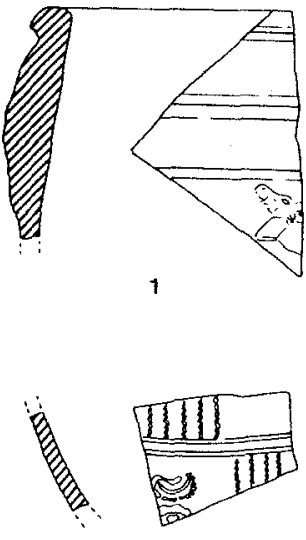

3

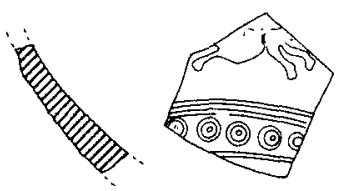

5
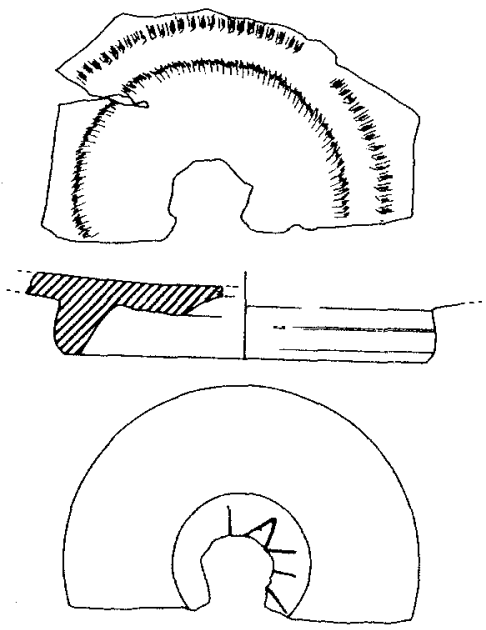

7

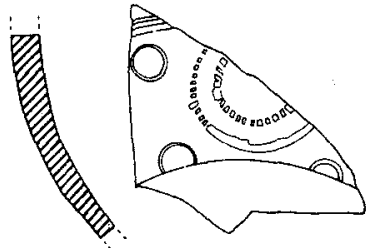

2

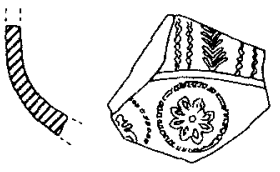

4

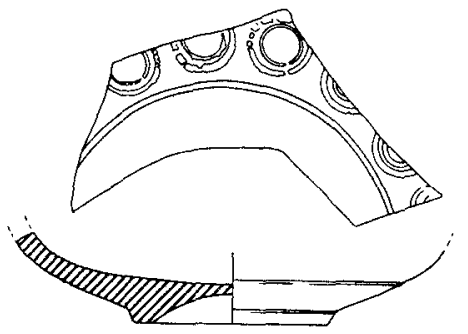

6

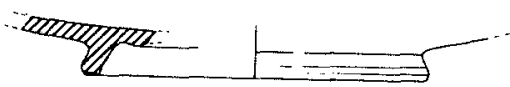

8

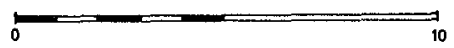

Figura 4. Terra Sigillata Hispánica. 
- Borde de almendra o Drag.37b (2203.1-2, figs. 3.5 y 4.1). Es la mejor serie de la producción hispánica, tanto por la calidad técnica como decorativa y también la más escasa. Reciben su nombre de la forma del borde, ligeramente inclinado hacia el interior y con labio en forma de almendra y son piezas de gran tamaño; características todas ellas presentes en nuestra pieza, decorada con un friso de ovas cerca del borde y con decoración de metopas en las que se situan diversos motivos de los que podemos identificar parte de uno vegetal ${ }^{4}$ y la cabeza de un ciervo ${ }^{5}$, que es uno de los motivos faunísticos más representativo de la sigillata del Valle del Ebro. Cronológicamente se situa en el último cuarto del s. I d.C. y el primer cuarto del s. II.

- Borde sencillo o Drag. 37a. Es la forma más abundante y contamos con numerosos fragmentos pertenecientes en su mayoría a la pared redondeada. Cronológicamente se sitúa en fechas similares a la forma 37 con borde de almendra. Los motivos decorativos pertenecen a los estilos característicos de la terra sigillata de Tricio, a excepción del estilo de imitación de las cerámicas galas:

- Un solo friso de círculos concéntricos segmentados separados por pequeños círculos y semicírculos (2200.2, fig. 4.2).

- Decoración de dos frisos de metopas superpuestos (2214.5, fig. 4.3).

- Dos frisos, el superior de metopas con líneas ondulantes y ángulos y el inferior con una sucesión de circulos segmentados con roseta interior de nueve pétalos (2209.4, fig. 4.4).

- Friso inferior con círculos concéntricos (2204.3, fig. 4.6).

- Parte de una posible decoración de metopas, de la que solamente se observa un animal y una pequeña orla inferior de círculos concéntricos simples (2204.4, fig. 4.5).

La cronología de la T.S.H. analizada se sitúa entre mediados del s. I d.C., momento de aparición de las formas Drag. 30, 15/17 y 27 y mediados del s. Il ya que aparecen numerosos fragmentos decorados con los típicos círculos del s. Il, cronología que coincide con el momento de mayor florecimiento de la T.S.H., establecido desde los Flavios hasta Trajano.

MAYet, F., op. cit., lám. CLIV. 903.

5 MAYET, F., op. cit., lám. CLXXXVIll.2093. 


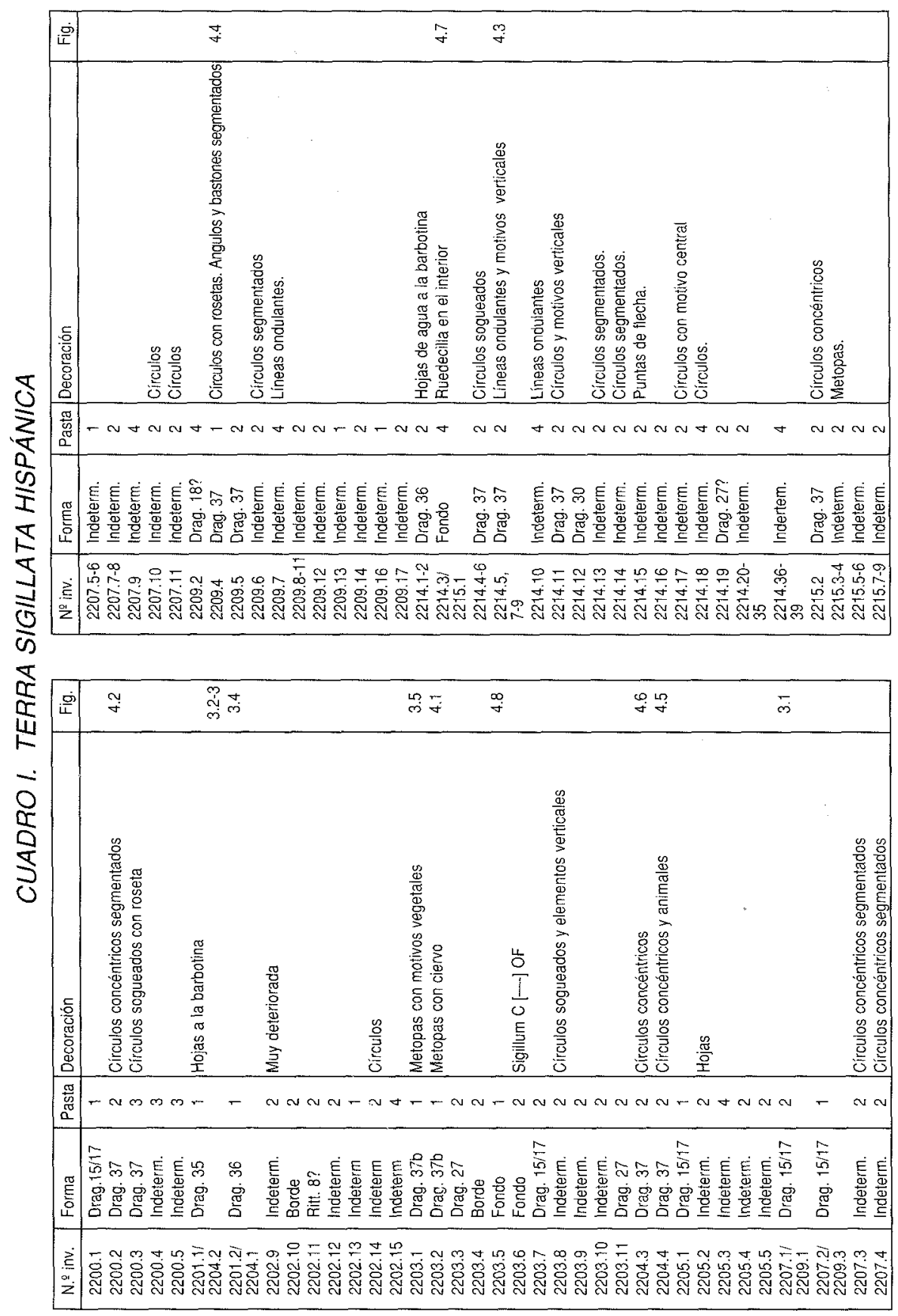




\subsection{Terra Sigillata hispánica avellana}

Este conjunto cerámico es con mucho el más significativo de cuantos se han hallado en la excavación, sobre todo porque, como veremos posteriormente, aporta nuevos ejemplares de formas escasamente representadas y matiza sensiblemente su cronología, ya que nos encontramos ante un conjunto de datación muy cerrada y concreta (cuadro II).

La citada producción se definió por vez primera en el yacimiento de Tiermes ${ }^{6}$, estableciendo una cronología comprendida entre la segunda mitad del s. I y la la primera mitad del s. II. En 1983-1984 Caballero y Juan establecen una tipología y la denominación de terra sigillata briIlante ?, fechando este tipo cerámico en los Ss. III y IV. Recientemente otros investigadores han remontado considerablemente su fecha, iniciando la producción a finales del s.l, con perduraciones hasta época bajoimperial, y estableciendo a su vez una nueva tipología basada en la terra sigillata hispánica ${ }^{8}$.

\subsubsection{Pastas}

Las pastas presentan las variaciones ya indicadas en los estudio sobre este tipo cerámico ${ }^{9}$ pero en su mayoría pueden definirse como de color pardo, ocre muy claro y en algunos casos rosáceo. Por lo que se refiere a los barnices presentan grandes diferencias dentro incluso de la misma pieza y oscila desde el ocre hasta el gris, si bien los fondos adquieren en muchos casos un tono anaranjado.

\subsubsection{Formas.}

Los numerosos fragmentos hallados pueden clasificarse en cuatro formas diferentes:

\footnotetext{
6 Argente Oliver, J.L. et alii, Tiermes I (E.A.E. 111), Madrid 1980, pp. 181-183.

7 Caballero, L., JuAN TOVAR, L.C., "Terra sigillata hispánica brillante», Empúries 45-46 (19831984), pp. 164-193.

\& Del Barrio Álvarez, Y., López Ambite, F., "La producción de Terra Sigillata Hispanica Avellana procedente del yacimiento de la Stma. Trinidad (Segovia)», BSAA LVII (1991), pp. 179-187.

\& Caballero, L., Juan Tovar, L.C., op. cit. pp.155-157; Del Barrio Álvarez, Y., López Ambite, F., op. cit. p. 180.
} 

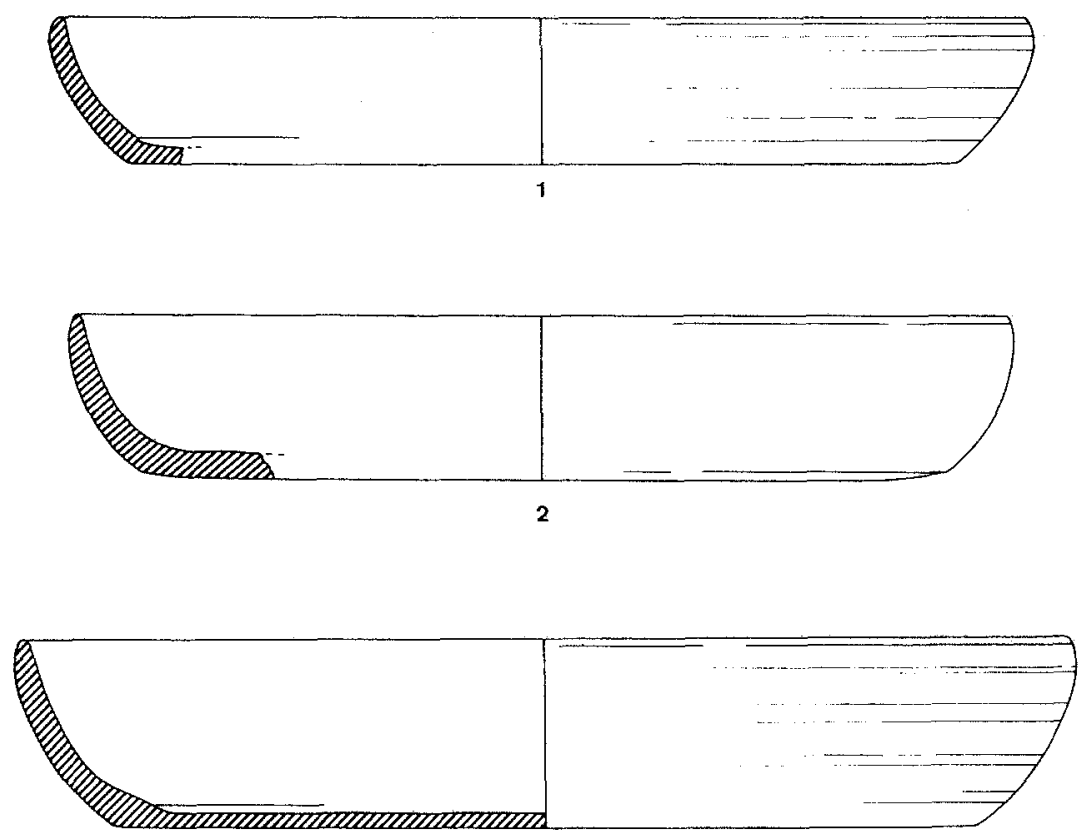

3

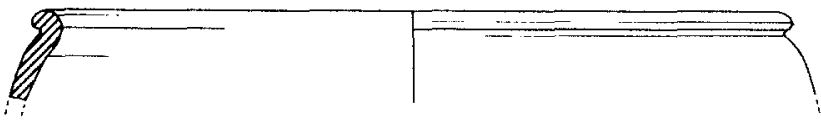

4

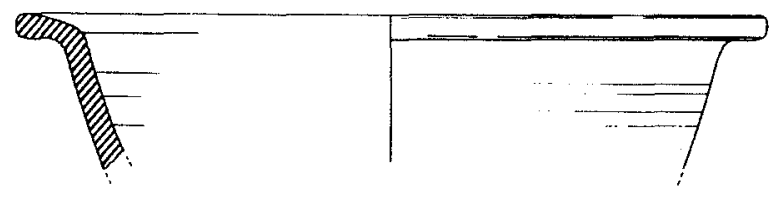

5

Figura 5. Terra Sigillata Hispánica avellana. 
- Hisp. 19/ Forma 9. Esta es la forma más común de este tipo de cerámica ya que del total de los ejemplares estudiados por Caballero y Tovar un $80 \%$ corresponden a este plato; esta mayoría también la constatamos en nuestro conjunto en el que contabilizamos al menos cuatro (2209.1819 , fig. $5.1 ; 2209.29 / 2214.40$, fig.5.2; 2209.30 y 2200.8/2210.1, fig.5.3), existiendo otros fragmentos pertenecientes a fondos que podrían pertenecer a tres de las citadas piezas, ya que el plato 2210.1 está completo. Dentro de los grupos establecidos por los autores corresponde al I, caracterizado por incluir los ejemplares más pequeños y de pared más delgada, con el labio sencillo, ya sea apuntado o redondeado, pero nunca regruesado ${ }^{10}$. La clara filiación con los platos de engobe interno rojo pompeyano, ya expuesta por diversos autores ${ }^{11}$ se hace en nuestro caso más patente por la presencia de una pequeña ranura interior (fig. 5.1 y 3).

- El fragmento 2200.9 (fig. 5.4) lo relacionamos con la forma Drag. 37 presente en las dos tipologías citadas con distintas variantes ${ }^{12}$.

- El fragmento 2200.6 (fig. 5.5) corresponde a un recipiente de forma abierta con labio horizontal y pared ligeramente redondeada, que no había sido constatado hasta el momento en los ejemplares publicados. Por lo que se refiere a su forma observamos una clara filiación con los cuencos de borde exvasado de cerámica común ${ }^{13}$.

- El fragmento 2200.7 corresponde a parte de un borde con el labio engrosado que se encuentra fracturado en el interior, por lo que es muy difícil definirse por alguna de las formas que presentan este tipo de labio.

Por lo que se refiere a la cronología de este grupo cerámico que, como hemos visto, Caballero y Juan situaron en el s. lil, debemos constatar que en nuestro conjunto cerámico no aparece ninguna otra pieza con esa fecha, por lo que la terra sigillata hispánica avellana convive con un grupo cerámico de finales del s. I y primera mitad del s. II, hecho que no hace sino corroborar la cronología ya publicada de otros yacimientos del centro peninsular, tales

\footnotetext{
10 Caballero, L., Juan Tovar, L.C, op. cit., fig. 6, p. 164.

11 Del barrio Álvarez, Y., Lopez Ambite, F., op. cit. p.181.

12 Caballero, L., Juan Tovar, L.C., op. cit. p. 166, fig. 17; Del Barkio Álvarez, Y., López AMBITE, F., op. cit. p.182, figs. 1-2.

13 Un ejemplar de cerámica común muy similar se ha hallado en las excavaciones de la Stma. Trinidad de Segovia: López AmbIte, F., Del Barfio Álvarez, Y., Excavaciones en la lglesia de la Stma. Trinidad (Segovia), ( Arqueología de Castilla y León. Memorias I). Junta de Castilla y León 1994, pp. 40-41. En el conjunto arqueológico se situa el ejemplar, clasificado como tipo $6 \mathrm{E}$, en la fase 1 que se fecha en el s. II, si bien el cuenco puede relacionarse con recipientes de tradición indígena presentes también en otros yacimientos de la Meseta.
} 
como Tiermes ${ }^{14}$, Uxama ${ }^{15}$, Complutum ${ }^{16}$, Villamanta (Madrid) ${ }^{17}$, Stma. Trinidad (Segovia) ${ }^{18}$, Segobriga ${ }^{19}$ y Sisapo (La Bienvenida, Ciudad Real) ${ }^{20}$.

\section{CUADRO II. TERRA SIGILLATA HISPANICA AVELLANA}

\begin{tabular}{|l|l|l|}
\hline № inv. & Forma & Fig. \\
\hline 2200.6 & Cuenco & 5.5 \\
\hline 2200.7 & Borde & \\
\hline $2200.8 /$ & Hisp. 19 & 5.3 \\
\hline 2210.1 & Drag. 37 & 5.4 \\
\hline 2200.9 & Hisp. 19 & \\
\hline 2203.12 & Indeterm. & \\
\hline 2204.6 & Hisp. 19 & \\
\hline 2206.1 & Hisp. 19 & \\
\hline $2209.18-19$ & Hisp. 19 & 5.1 \\
\hline $2209.20-29 /$ & Hisp. 19 & 5.2 \\
2214.40 & Hisp. 19 & \\
\hline 2209.30 & & \\
\hline
\end{tabular}

\subsection{Cerámica vidriada}

Aunque los fragmentos hallados son escasos y no se pueden asignar a una forma ni a un taller, es necesario mencionar su existencia, ya que de

14 ARgente, J.L. et alii., op. cit. 1980, pp. 182-183. ARgenTE, J.L. et alii, Tiermes /I. Campañas de 1979 y 1980. Excavaciones realizadas en la ciudad romana y en la Necrópolis Medieval, (E.A.E.128), Madrid 1984, pp. 203-204, 272-273 y 285 ss. ARGENTE, J.L. et alii, Tiermes IV. La Casa del Acueducto (Domus Alto imperial de la ciudad de Tiermes) (Campañas 97-1986) (E.A.E. 167), Madrid 1994, pp. 147-149.

15 Garcia Merino, C., Uxama I (Campañas de 1976 y 1978): Casa de la Cantera, Casa del Sectile, "El Tambor», (E.A.E. 170), Madrid 1995, p. 72, fig. 23 11. En el nivel II de la Casa de la Cantera aparece un fragmento de plato de la forma 9 . El nivel se fecha en época flavia.

16 Datos inéditos suministrados verbalmante por $\mathrm{S}$. Rascón, a quien agradecemos su información.

17 En las excavaciones realizadas en los últimos años se halló un fragmento que imita claramente una forma 27 de terra sigillata hispánica. Agradecemos a la Dra. Mar Zarzalejos la posibilidad de incluir este dato inédito.

18 Del Barrio Álvarez, Y., López Ambite, F., op. cit. 1991, p. 185 y op. cit. 1994, pp. 25-26.

19 Almagro Gorbea, M. y Lorrio Alvarado, A., Segóbriga III. La muralla Norte y la Puerta Principal, Cuenca 1989, pp. 33-34, 44, 60 y ss. Aunque no aparezca en contextos estratigráficos claros, sí lo hace asociado con materiales de los ss. I y $\|$ d.C.

20 FERnÁNDEZ OCHOA, C. et alii, Sisapo I. Excavaciones arqueológicas en La Bienvenida, Patrimonio Histórico de Castilla La Mancha 1994, p. 111. 
las ciudades del centro peninsular únicamente Complutum había proporcionado algunos fragmentos ${ }^{21}$.

\subsection{Cerámica de paredes finas}

Contamos con varios ejemplares de estos vasos o tacitas destinadas sobre todo a la bebida (vasa potoria), cuya característica esencial es la delgadez de sus paredes (cuadro III).

Únicamente conservamos dos bordes, ambos de la forma Mayet XL (2200.13/2202.1, fig. 6.1 y 2 y 2203.13 , fig. 6.3 ) que ha sido datada por la autora en un lapso de tiempo que oscila desde Tiberio-Claudio hasta los Flavios ${ }^{22}$. Solamente el primero de los vasos está decorado con lúnulas de barbotina, siendo este procedimiento uno de los más empleados por los talleres provinciales del s. I d.C.

El resto de los fragmentos son de escasa entidad y su tamaño y forma impiden la clasificación tipológica; por lo que se refiere a la decoración se constata la ruedecilla en los fragmentos 2206.2 y 2214.41 .

Las pastas podemos clasificarlas en dos grupos, en ambos casos muy depuradas:

- Pasta gris (2206.3-4/2205.6-9; 2200.13/2202.1 y 2214.41).

- Pasta marrón (2206.2 y 2203.13).

Las características de las citadas piezas impiden relacionarlas con los talleres itálicos, galos o hispanos conocidos hasta el momento; por lo que la posible procedencia de algún taller situado en las cercanías debe tenerse en cuenta, máxime cuando un pequeño fragmento hallado en Complutum parece responder a las mismas características decorativas con lúnulas a la barbotina y a idéntica pasta de color gris ${ }^{23}$.

La constatación de la presencia de esta familia cerámica en Madrid añade un punto más al mapa de dispersión en la zona central peninsular que en 1990 quedaba completamente vacío ${ }^{24}$, y en el que actualmente se pueden añadir Madrid, Complutum ${ }^{25}$ y Segovia ${ }^{26}$.

\footnotetext{
21 Información suministrada verbalmente por S. RASCón.

22 MAYET, F. Les céramiques à parois fines dans la Peninsule lbérique, París 1975, pp. 72-73.

23 Fernández Galiano, D., Complutum I. Excavaciones (E.A.E. 137), Madrid 1984, fig. 178, no 426 , p. 320 .

24 Beltrán, M., Guía de la cerámica romana, Zaragoza 1990, figs. 83-84.

25 Fernández Galiano, D., op. cit., pp. 433-434.

26 López Ambite, F., Del BarRio Álvarez, Y., op. cit. 1994, p.49, se documentan cuatro ejemplares de este tipo cerámico.
} 

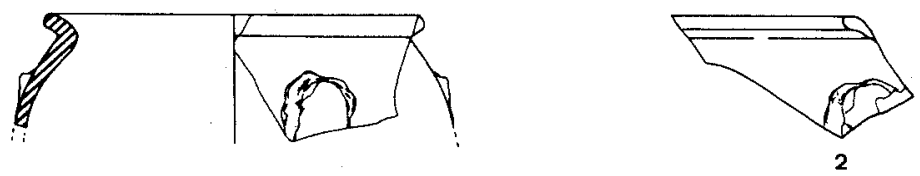

1

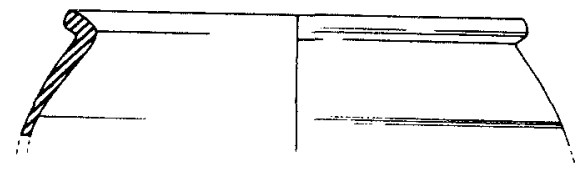

3
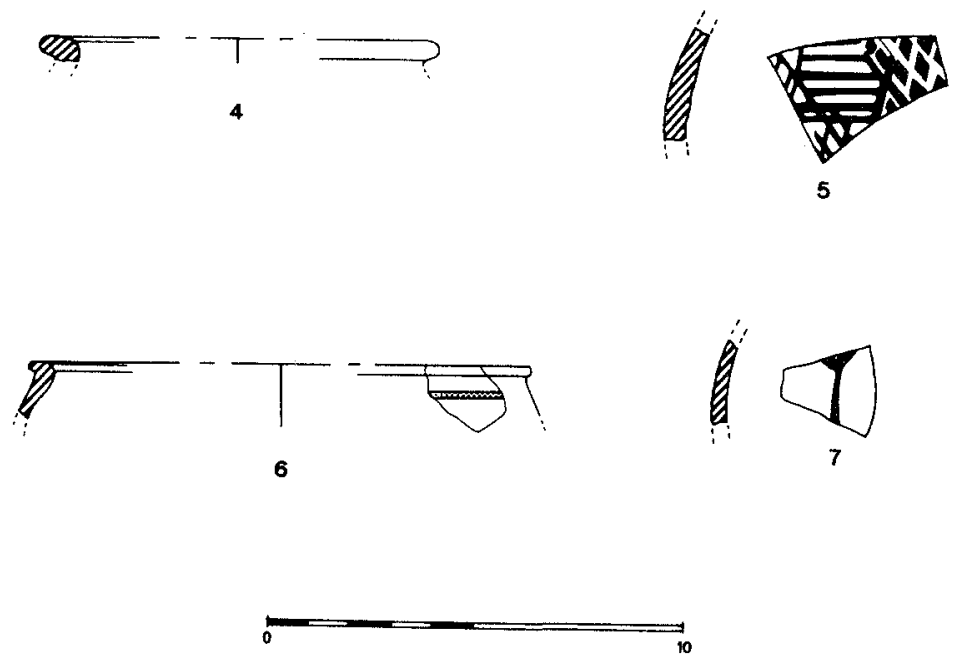

Figura 6. Cerámica de paredes finas (1-3). Cerámica pintada de tradición indígena (4-7) 


\section{CUADRO III. CERÁMICA DE PAREDES FINAS}

\begin{tabular}{|l|l|l|l|l|}
\hline № inv. & Forma & Pasta & Decoración & Fig. \\
\hline $2200.13 / 2202.1$ & Mayet XL & Gris & Lúnulas a la barbotina & $6.1-2$ \\
\hline 2203.13 & Mayet XL variante & Marrón & & 6.3 \\
\hline $2205.6-9 / 22006.3-4$ & Indeterm. & Gris & & \\
\hline 2206.2 & Indeterm. & Marrón & Ruedecilla & \\
\hline 2214.41 & Indeterm & Gris & Ruedecilla & \\
\hline
\end{tabular}

\subsection{Cerámica pintada}

Existen numerosos fragmentos de cerámica pintada, denominada de tradición indígena, todos ellos de tamaño muy pequeño, por lo que su clasificación se hace muy ardua (cuadro IV). Unicamente el fragmento de borde 2214.42 (fig. 6.4) parece corresponder a la foma 18A de Abascal, producida por los talleres de Segobriga ${ }^{27}$ con la característica pasta anaranjada y la pintura roja sobre el que se pinta de color negro. También la decoración de ajedrezado del fragmento 2200.10 (fig. 6.5) es característica de los mismos talleres.

\section{CUADRO IV. CERÁMICA PINTADA DE TRADICIÓN INDIGENA}

\begin{tabular}{|l|l|l|l|}
\hline № Inv. & Forma & Decoración & Fig. \\
\hline 2200.10 & Indeterm. & Ajedrezado & 6.5 \\
\hline 2200.11 & Indeterm. & & \\
\hline 2200.12 & Indeterm. & & \\
\hline 2204.8 & Ollita & Filete negro & 6.6 \\
\hline 2209.35 & Indeterm. & Filete negro & \\
\hline 2209.36 & Indeterm. & Filete negro & \\
\hline 2214.42 & Abascal 18A & & 6.4 \\
\hline $2214.44-46$ & Indeterm. & Motivo sin identificar & 6.7 \\
\hline
\end{tabular}

Por lo que se refiere al conjunto formado por varios fragmentos (2200.11; 2204.8, fig. 6.6; 2209.36 y 2214.44-46, fig. 6.7), todos ellos parecen pertenecer a la misma pieza o, al menos, al mismo taller que, por el

27 ABASCAL, J.M., La cerámica pintada romana de tradición indigena en la Península Ibérica, Madrid 1986, pp. 110-111. 
momento no podemos definir, si bien no debemos olvidar la existencia de otros centros productores en la Meseta Sur, al N. de la provincia de Toledo y en las cercanías de Villaverde (Madrid).

En relación a la cronología, los talleres de la Meseta Sur centran su producción desde mediados del s. I d.C., incluyendo también parte del s. II d.C.

\subsection{Cerámica común de mesa}

Son muy pocos los ejemplares de este tipo cerámico (cuadro $V$ ) y se resumen a dos botellas de cerámica oxidante con engobe de color rojo en el cuerpo (2209.34, fig. 7.1 y 2203.15, fig. 7.2); este tipo de recipientes se utilizaban para servir vino u otros líquidos ya que el estrecho cuello impedía otros usos. Una de ellas presenta el borde con una moldura, hecho que parece característico del s. II d.C.

\section{CUADRO V. CERÁMICA COMÚN DE MESA}

\begin{tabular}{|l|l|l|l|l|l|}
\hline NN inv. & Forma & Cocción & Barniz/Engobe & Decoración & Fig. \\
\hline 2202.2 & Botella & Oxidante & Rojo & & 7.4 \\
\hline 2202.81 & Plato & Oxidante & & & 7.3 \\
\hline 2204.7 & & & & & \\
\hline 2203.15 & Botella & Oxidante & Rojo & & 7.2 \\
\hline 2203.17 & Botella & Oxidante & & & 7.5 \\
\hline 2203.18 & Asa & Oxidante & & & 7.6 \\
\hline $2203.20-31$ & Indeterm. & Oxidante & & & \\
\hline $2204.16-22$ & Indeterm. & Oxidante & & & \\
\hline $2205.11-15$ & Indeterm. & Oxidante & & & \\
\hline $2206.7-12$ & Indeterm. & Oxidante & & & \\
\hline 2207.15 & Fondo & Reductora & & & \\
\hline $2207.17-18$ & Indeterm. & Oxidante & & & \\
\hline $2209.31-32$ & Indeterm. & Reductora & Negro & & \\
\hline 2209.33 & Indeterm. & Oxidante & & Acanaladuras & 7.7 \\
\hline 2209.34 & Botella & Oxidanie & & & 7.1 \\
\hline
\end{tabular}

Por lo que se refiere al plato, su característica fundamental es la banda de color oscuro situada en el exterior del borde y que se debe a las peculiaridades de la cocción, ya que en el horno los recipientes estaban apilados 

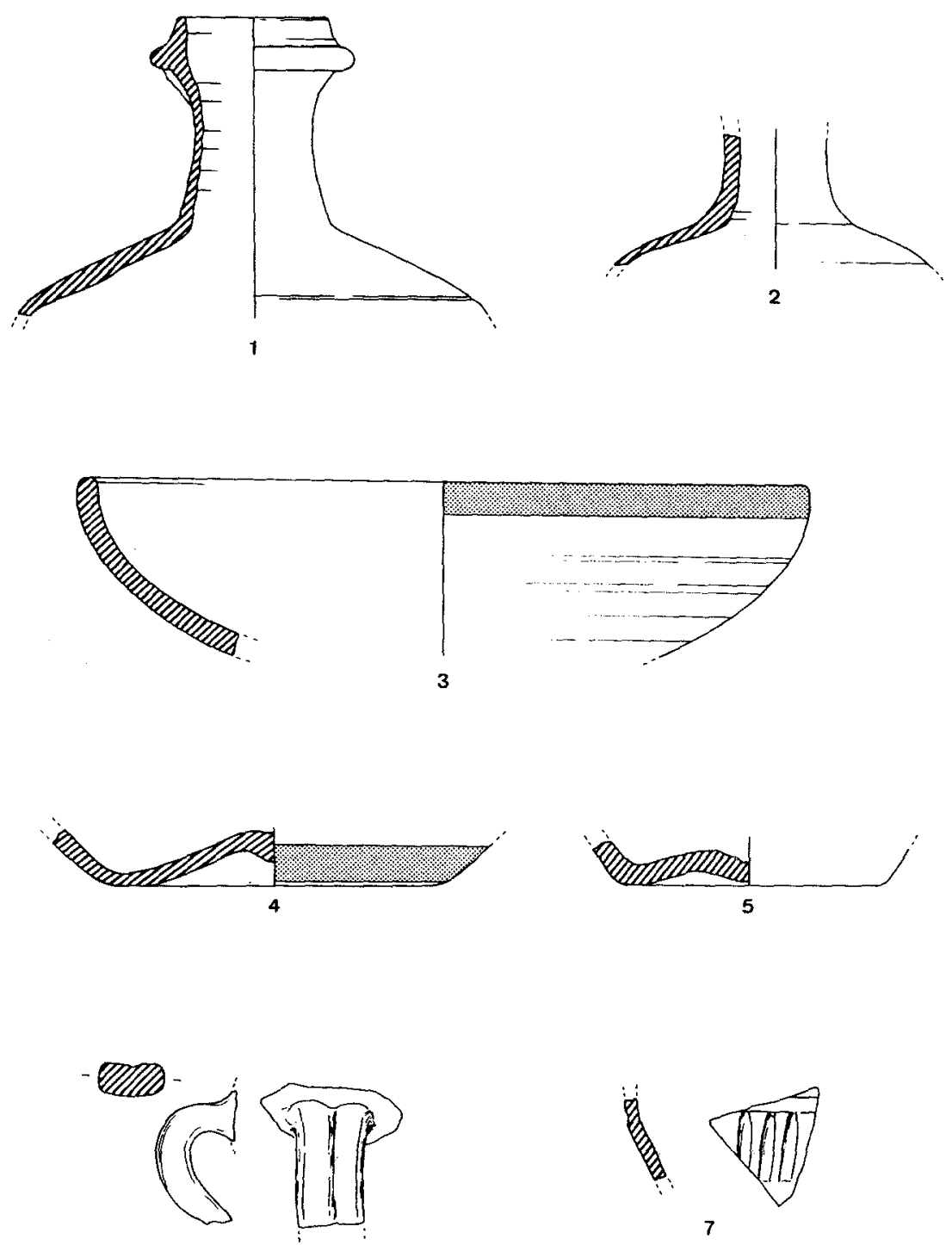

6

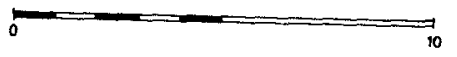

Figura 7. Cerámica común de mesa. 
uno dentro de otro, por lo que la última de las fases, reductora, produjo la banda oscura en la única zona visible (2204.7, fig. 7.3) ${ }^{28}$.

Es probable que los dos fondos umbilicados (2202.2, fig. 7.4 y 2203.17 , fig. 7.5) correspondan también a botellas o jarras y lo mismo sucede con la pequeña asa con acanaladura central (2203.18, fig. 7.6).

Sólo las dos botellas parecen proceder del mismo alfar, siendo el resto de las pastas de diferentes características.

\subsection{Cerámica de cocina}

En este apartado se incluyen todos los recipientes empleados en la preparación de alimentos, ya sea para su cocción (cazuelas y ollas) o para la manipulación en frío (morteros) (cuadro VI).

Los ejemplares conservados proceden del mismo alfar ya que no sólo las formas son muy similares, sino que también la pasta responde a las mismas características: color rojizo con granulometría media y desgrasante grueso, en el que se adivinan gránulos de mica. Aunque en general son muy toscas, presentan el acabado más cuidado en el exterior. La superficie exterior e interior se encuentra muy quemada, posiblemente por su continuado uso en el fuego.

- Cazuelas. Solamente conservamos un ejemplar (2202.4, fig. 8.1) que presenta la característica abertura de la boca más ancha que el resto del cuerpo y un cuerpo esférico u ovoide. Por lo que se refiere al borde está doblado hacia el exterior y se engrosa en el extremo del labio; es muy similar al tipo II de las ollas que analizaremos posteriormente.

- Ollas. Estos recipientes se caracterizan por tener la abertura de la boca menor que el diámetro del cuerpo. Se conservan numerosos ejemplares que hemos clasificado en tres tipos diferentes:

Tipo 1. Se caracteriza por los bordes engrosados de sección circular (2207.14, fig. 8.3) u ovoide (2209.43, fig. 8.2 ) y el cuello muy corto.

Tipo II. Presenta el cuello desarrollado y el borde alargado y doblado hacia el exterior; se constatan tres tipos diferentes de labios:

28 En el cercano yacimiento de la Stma. Trinidad, se denomina tipo $6 \mathrm{~A}$; la banda cercana al borde está, según los autores, pintada: Del BarRio ÁlvaREZ, Y., LóPEZ AmBITE, F., op. cit. 1994, pp. 39-40. Aparecen en las fases 2 y 1 que se fechan en la segunda mitad del s. I y s. II respectivamente. 


\section{CUADRO VI. CERÁMICA COMÚN DE COCINA}

\begin{tabular}{|c|c|c|c|}
\hline № inv. & Forma & Cocción & Fig. \\
\hline 2200.14 & Olla. III. 2 & Oxidante & 9.5 \\
\hline $2202.3 / 2204.13$ & Olla. 11.3 & Oxidante & 9.2 \\
\hline 2202.4 & Cazuela & Oxidante & 8.1 \\
\hline 2202.5 & Fondo plano & Oxidante & \\
\hline 2202.6 & Olla. III. 1 & Oxidante & 9.4 \\
\hline 2202.7 & Cuenco/Tapa. & Oxidante & 11.2 \\
\hline $2203.14 / 2204.9-10$ & Olla. III.2 & Oxidante & 10.6 \\
\hline 2203.19 & Mortero & Oxidante & \\
\hline 2204.11 & Olla. III. 2 & Oxidante & \\
\hline 2204.12 & Olla. Ill.1 & Oxidante & 9.3 \\
\hline $2204.23-46$ & Indeterm. & Reductora & \\
\hline $2205.10 / 2207.12$ & Mortero & Oxidante & 11.1 \\
\hline $2205.11-15$ & Indeterm. & Oxidante & \\
\hline $2206.5 / 2209.44$ & Olla. III.2 & Oxidante & 9.6 \\
\hline 2206.6 & Olla. 11.2 & Oxidante & 9.1 \\
\hline $2206.13-51$ & Indeterm & Oxidante & \\
\hline $2207.13 / 2209.45$ & Olla. III.2 & Oxidante & 10.1 \\
\hline 2207.14 & Olla. 1 & Oxidante & 8.3 \\
\hline $\begin{array}{l}2207.16 / \\
2209.37-38 / \\
2209.42\end{array}$ & Olla. II.1 & Reductora & 8.4 \\
\hline $2207.19-78$ & Indeterm. & Reductora & \\
\hline 2209.39 & Olla. III.2 & Oxidante & 10.2 \\
\hline 2209.40 & Olla.III.2 & Oxidante & 10.3 \\
\hline 2209.41 & Olla. III.2 & Oxidante & 10.4 \\
\hline 2209.43 & Olla. 1 & Oxidante & 8.2 \\
\hline $2209.48-153$ & Indeterm. & Reductora & \\
\hline 2214.52 & Olla. III.2 & Oxidante & 10.5 \\
\hline 22014.53-145 & Indeterm. & Reductora & \\
\hline
\end{tabular}

II.1. Labio de extremo facetado (2207.16/2209.37-38/2209.42, fig. 8.4)

11.2. Labio de extremo apuntado (2206.6, fig. 9.1).

II.3. Labio de extremo redondeado y zona superior horizontal (2202.3/2204.13, fig.9.2). 

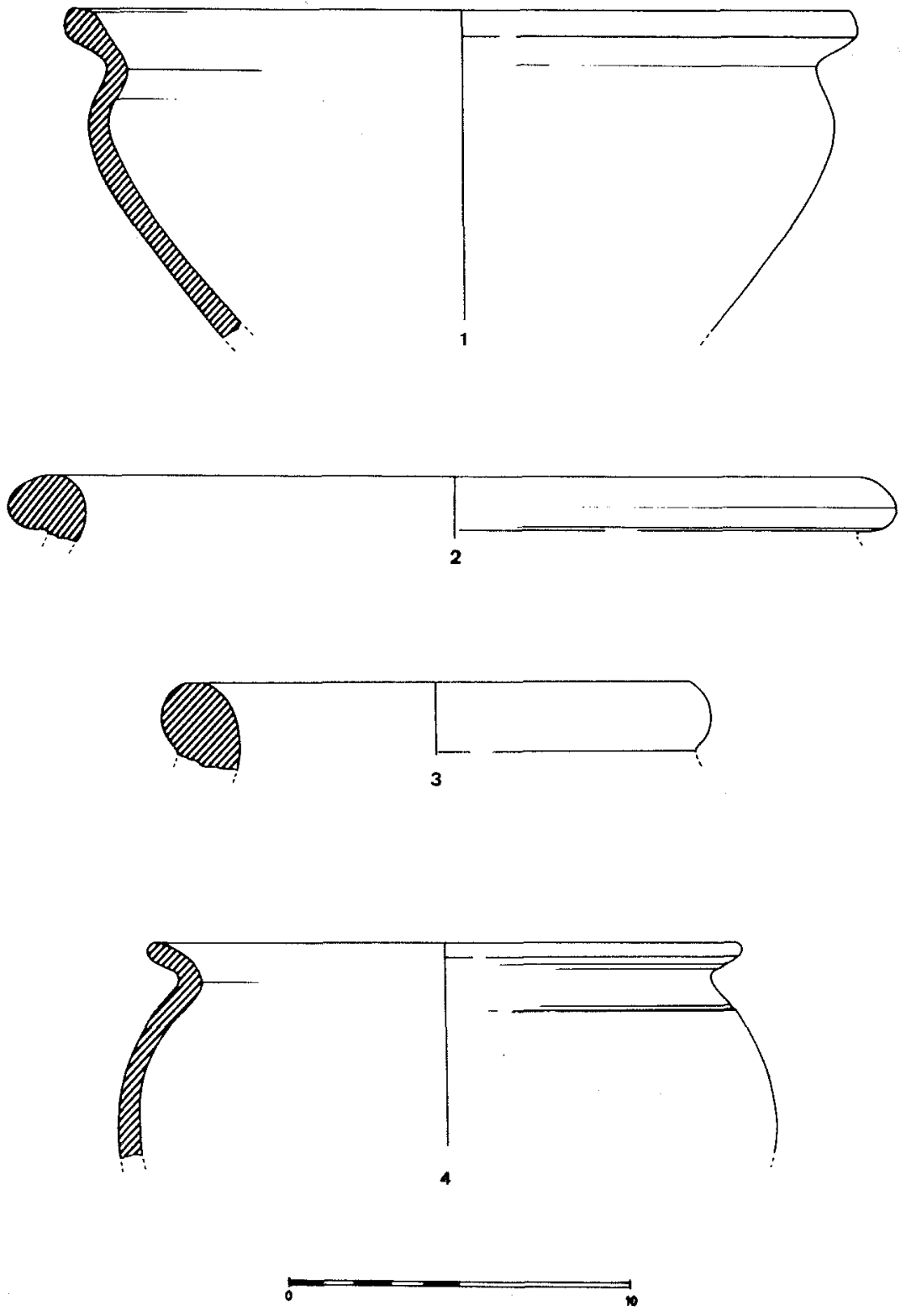

Figura 8. Cerámica común de cocina: Cazuela (1); ollas tipo / (2-3); ollas tipo Il.1 (4). 

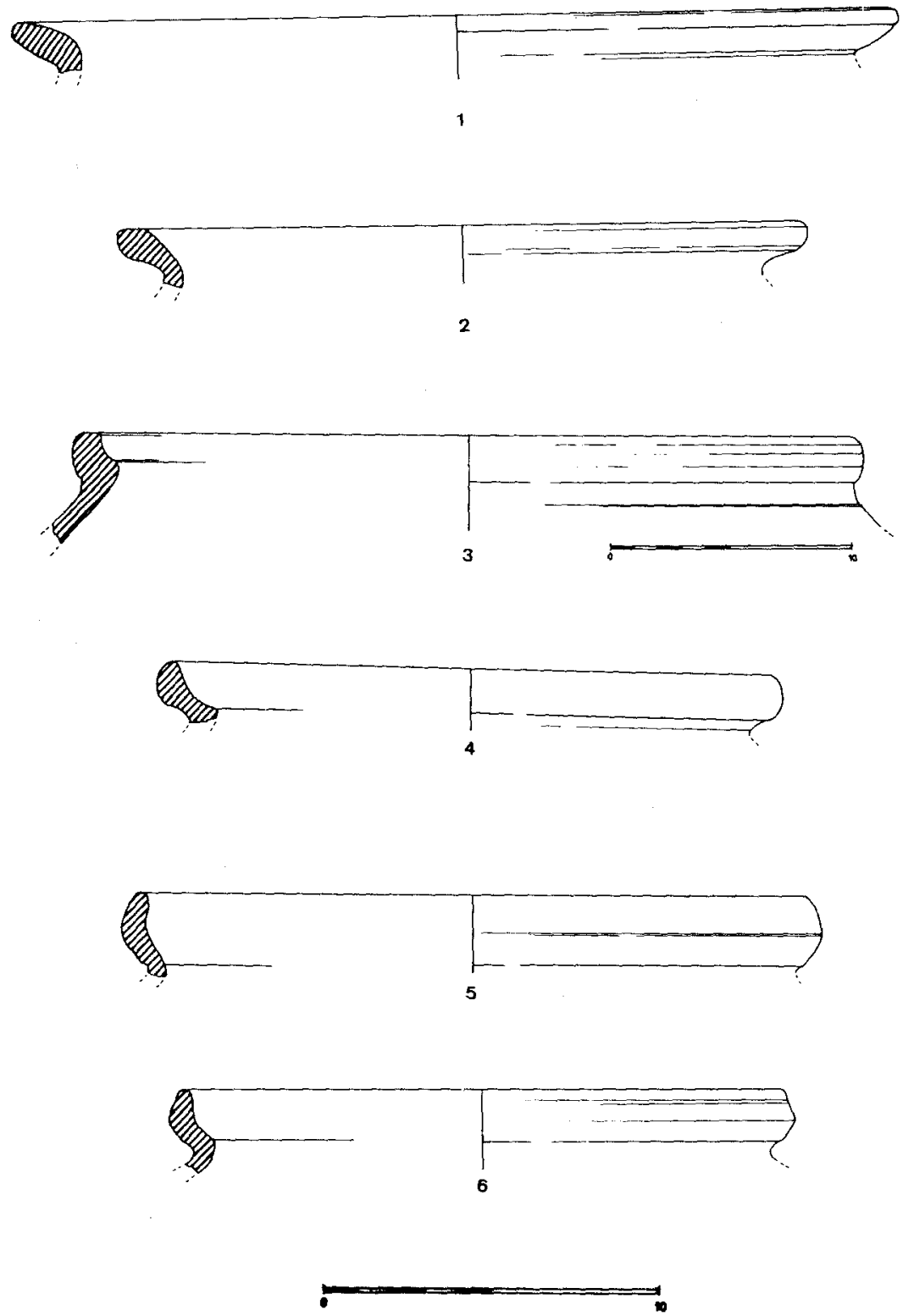

Figura 9. Cerámica común de cocina: Ollas tipo II.2 (1); ollas tipo II.3 (2); ollas tipo III.1 (34); ollas tipo III.2 (5-6). 
En líneas generales este tipo de olla, con diferentes variantes, aparece en la mayoría de los yacimientos romanos y se puede relacionar con el denominado tipo 1 de $M$. Vegas ${ }^{29}$.

Tipo III. Bordes verticales, más o menos engrosados, con acanaladura o entalle interior para encajar la tapadera. Los cuellos están marcados, pero poco desarrollados. En relación al labio encontramos:

III.1. Labio engrosado (2204.12, fig. 9.3).

III.2. Labio poco engrosado (2200.14, fig. 9.5; 2202.6, fig. 9.4; $2203.14 /$ 2204.9-10, fig.10.6; 2204.11; 2206.5/2209.44, fig.9.6; 2207.13/2209.45, fig. $10.1 ; 2209.39$, fig. 10.2; 2209.40, fig. 10.3; 2209.41, fig. 10.4; 2214.52, fig.10.5). En alguna de estas ollas se encuentra una canaladura poco marcada en el labio exterior (2209.41, fig. 10.4).

Esta olla se relaciona con la $1 \mathrm{~A}$ de $\mathrm{M}$. Vegas por el hecho de presentar la ranura para las tapaderas, hecho que se repite, con muchas variantes, en las cerámicas de distintos yacimientos de la zona central ${ }^{30}$.

Aunque la proximidad geográfica nos podría llevar a plantear la posibilidad de un mismo alfar para nuestra cerámica de cocina y la del yacimiento de la Stma. Trinidad de Segovia, las características técnicas no coinciden, ya que la cerámica del citado yacimiento presenta la pastas de color gris ${ }^{31}$.

- Cuenco o tapadera. El recipiente 2202.7 (fig. 11.2) pudo tener cualquiera de los dos usos e incluso ambos de forma simultánea. Destacar que las estrías de la superficie exterior del pivote son las que deja el cordel usado para separar la pieza cerámica del torno.

- Morteros. Como ya se ha expuesto al principio no se usaba para elaborar platos calientes, sino para descortezar el grano, fabricar el pan y preparar salsas. Conservamos dos ejemplares:

- Uno de ellos de pequeño tamaño y borde horizontal que pertenece al mismo alfar que el resto de los recipientes descritos (2205.10/2207.12, fig. 11.1).

29 Del Barrio Álvarez, Y., López Ambite, F., op. cit. 1994, pp. 35-36, en la tipología de la Stma. Trinidad corresponde al tipo 1 caracierístico de las fases 2 y 1.

30 Del Barrio Álvarez, Y., López AmBite, F., op. cit. 1994, pp. 36-37; en estas páginas se exponen todos los paralelos existentes en los yacimientos hispanos de zonas cercanos; la cronología en la Stma. Trinidad es la misma que la expuesta para otros recipientes de cerámica común, segunda mitad del s. I y s. II.

31 Del Barrio Álvarez, Y., López Ambtte, F., op. cit. 1994, p. 35. 

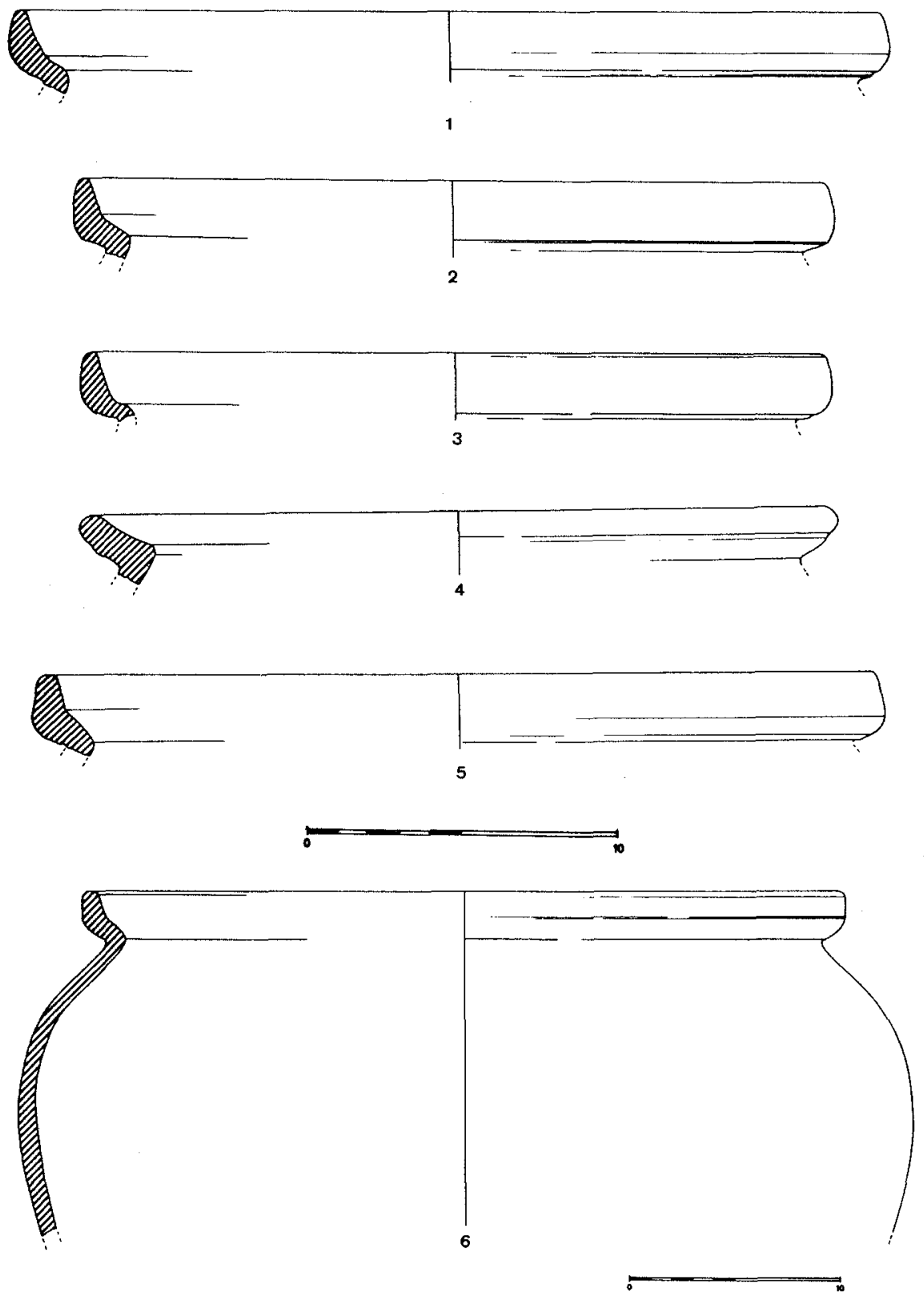

Figura 10. Cerámica común de cocina: Ollas tipo III.2. 
- El fragmento informe del mortero 2203.19 presenta características diferentes, ya que la pasta es muy depurada, de color ocre; por lo que se refiere a las piedrecillas que se insertaban en la superficie interior cuando la arcilla estaba aún fresca, son muy gruesas y de color rojo ladrillo. A simple vista y en espera de los análisis, podemos plantear la posibilidad de que provenga del alfar de Tarazona ${ }^{32}$.

\subsection{Cerámica de transporte y almacenaje}

De estos recipientes usados para conservar o transportar vino y aceite, conservamos dos fragmentos del cuerpo de una o varias ánforas y el fondo de un dolium (2203.16, fig.11.3).

\subsection{Lucernas}

Hay que destacar la existencia de un solo fragmento de lucerna correspondiente a la parte inferior del pico (2214.51).

\subsection{Pondera}

En un mismo nivel (2208, fig. 12.1) aparecen tres pesas de telar del mismo tamaño y características, cuya pasta es muy similar a la de la cerámica de cocina.

\subsection{Metales}

Solamente se han hallado cuatro clavos de hierro fragmentados y una pieza de hierro de forma semicircular muy deteriorada.

\subsection{Hueso.}

Los hallazgos óseos se reducen a un acus crinales o aguja de pelo, cuya función principal, como su nombre indica es sujetar el cabello femenino.

32 Aguado OTAL, C. «Avance al estudio de un posible alfar romano en Tarazona: IV. La cerámica común», Turiaso IV (1985), pp. 28-32. 


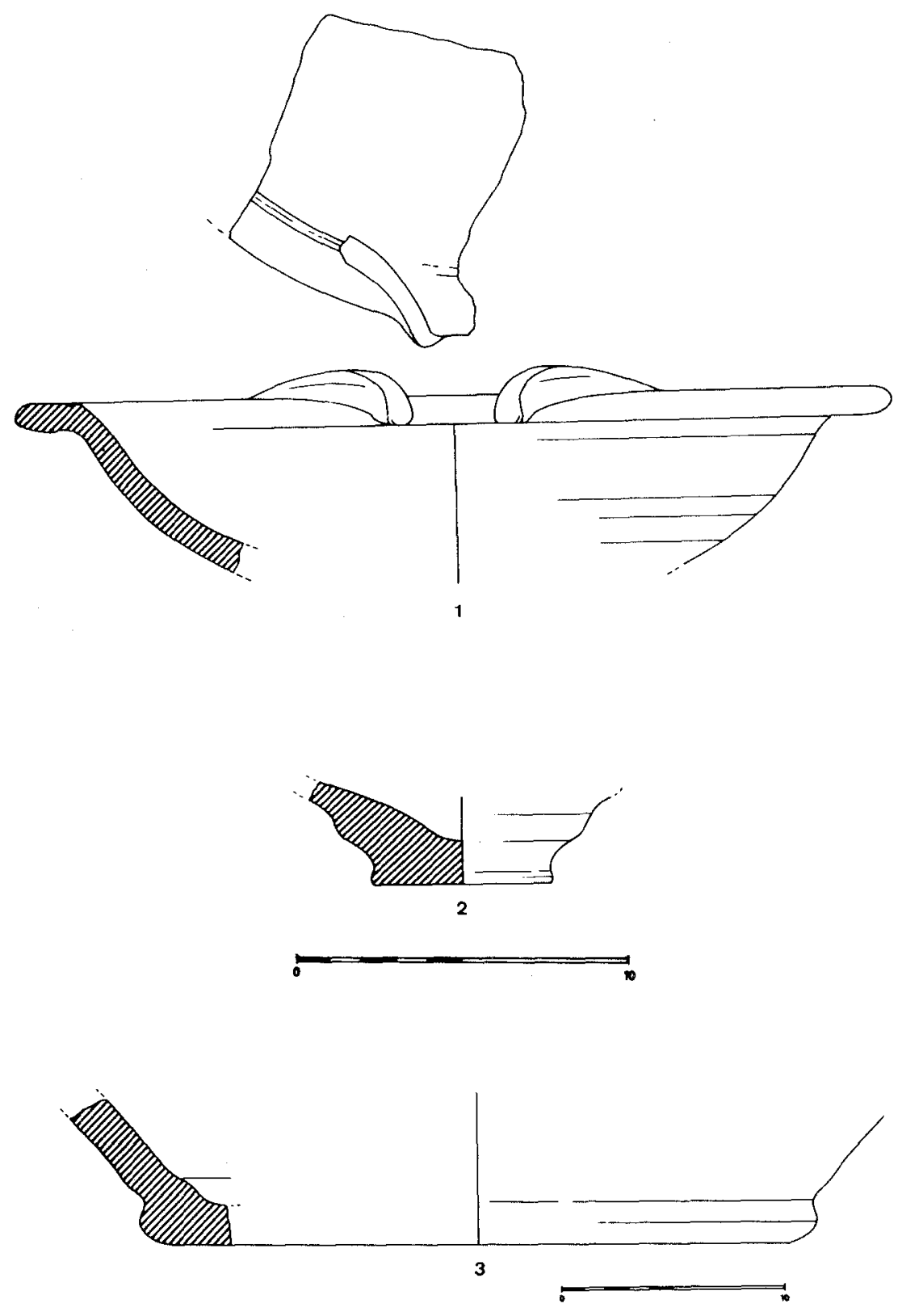

Figura 11. Cerámica común de cocina: Mortero (1); cuenco (2). Dolium (3). 
El acus presenta una de las formas más comunes de este tipo de objetos: cabeza cilíndrica que termina de forma plana en la zona de contacto con el cuello, cuerpo de sección circular con engrosamiento en la parte superior y finalmente la punta, conservada perfectamente en nuestro ejemplar.

Morfológicamente se corresponde con el denominado tipo II b de la tipología establecida para los acus de la vecina ciudad romana de Complutum donde se fechan desde la segunda mitad del s. I d.C. hasta el s. $v^{33}$.

\subsection{Material de construcción}

Es notable el hecho de que aparezcan un gran número de tejas, ya sean tegulae o imbrices (figs. 12.2-3). Hay que destacar la pequeña curva de los imbrices y el reborde poco acusado de las tegulae. Estas características implican una realización absolutamente local que contrasta con los restos cerámicos que implican unos hábitos de vida muy romanizados.

\section{CRONOLOGÍA}

Del análisis estratigráfico se deriva, como hemos expuesto al comienzo, que todo el basurero es de una misma época; un estudio en profundidad de los restos cerámicos nos permite corroborarlo ya que las mismas formas aparecen en distintos niveles y todas ellas ofrecen una cronología semejante que oscila entre época flavia y mediados del s. "I d.C. No queremos olvidar la presencia en el estrato más profundo de un fragmento de la forma Drag. 30 de T.S.H. que parece ser la más antigua, ya que aparece a mediados del s. I y su producción cesa a finales del mismo; por otro lado en el estrato superior aparecen los tres fragmentos de T.S.H. de la pasta tipo 3 con un barniz anaranjado que parece responder a las producciones de Tricio del s. II; sin embargo consideramos ambos hechos anecdóticos ya que conviven con piezas cerámicas idénticas en los dos casos, como son la T.S.H. avellana y la cerámica pintada de tradición.

33 Rascon, S. et alii, "Contribución al conocimiento de algunas producciones de hueso de la ciudad hispanorromana de Complutum: el caso de las acus crinales", Espacio, Tiempo y Forma. Prehistoria y Arqueología 8 (1995), pp. 315-316. 

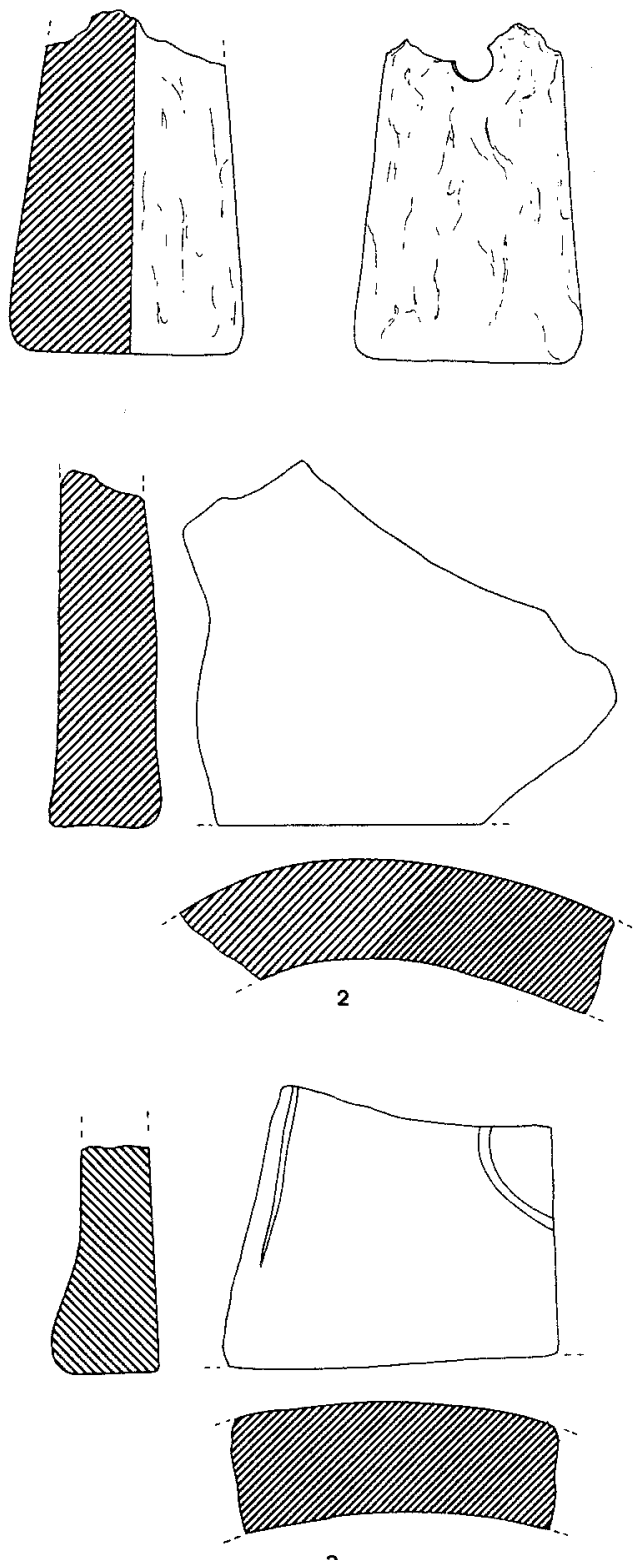

3

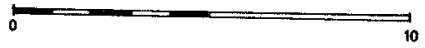

Figura 12. Pondus (1). Imbrex (2); tegula (3). 
En un primer momento, solamente la T.S.H. avellana parecía ser la nota discordante con la homogeneidad cronológica, puesto que de forma teórica se fechaba desde finales del s. II hasta el s. IV, data que no puede aplicarse a los restos que estudiamos claramente anteriores, como hemos indicado anteriormente y que además coincide con otros yacimientos de cronologías similares, como Tiermes, Uxama, Complutum y sobre todo la Stma. Trinidad de Segovia, que ya hemos analizado en el apartado correspondiente.

Por lo que se refiere a estratigrafías similares en la zona central de la Península, hay que citar el yacimiento de la Stma. Trinidad de Segovia, sobre todo en la denominada fase 2 , que es el momento en el que la sociedad indígena comienza a transformarse al integrarse Segovia en el ámbito cronológico romano, algo más retrasada que las ciudades de la Meseta más próximas al Valle del Ebro ${ }^{34}$.

\section{UNA VILLA EN LA ORILLA DEL MANZANARES}

El análisis de los materiales también conduce a otro tipo de reflexiones, entre las cuales destaca la escasez de vasijas de almacenaje, como hemos visto en el apartado 3.8., lo cual nos induce a considerar la posibilidad de que el basurero no pertenezca a un hábitat con estructuras de producción agrícola. Por otro lado, el tamaño relativamente pequeño del basurero nos acerca a una vivienda de tamaño medio, cuyos habitantes ostentaban un cierto nivel económico, hecho que avala el estudio de la cerámica de mesa, muy abundante y prácticamente toda ella de lujo ya que el porcentaje de la común de mesa es realmente escaso en relación al conjunto de terra sigillata y a los vasos de paredes finas. Hay que señalar además la escasez de ánforas, de las que únicamente se encontraron dos fragmentos informes de pequeño tamaño, hecho ya constatado en otros yacimientos de la zona central y que supone la llegada de los productos en otro tipo de envases de carácter perecedero.

No es éste el único hallazgo de un basurero ligado a una villa en la región madrileña, ya que en las proximidades de la villa de Villaverde Bajo se hallaron ... «hoyos rellenos de tierra negra, cenizas, huesos de animales, cerámica negra y tosca y terra sigillata» ${ }^{35}$.

34 Del Barrio Álvarez, Y., López Ambite, F.y op. cit. 1994, p. 56.

35 PÉrez de Barradas, J., "Las villas romanas de Villaverde Bajo (Madrid)", Anuario de Prehistoria Madrileña II-III (1931-1932), pp. 120-121. 
Las villas romanas a orillas del Manzanares no son un hecho extraño y la mayor concentración de asentamientos se observa en los valles del Guadarrama y del conjunto Manzanares-Henares-Jarama especialmente en su curso bajo, caracterizado por la fertilidad de las tierras y por la cercanía de importantes vías de comunicación.

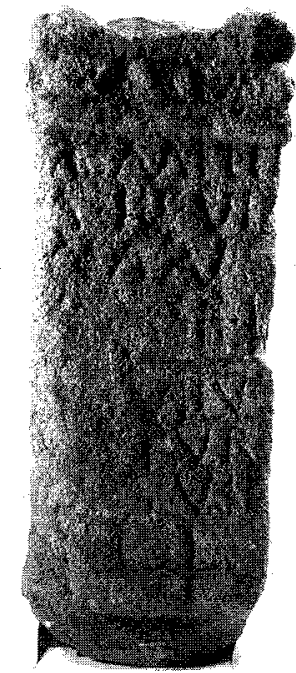

Lámina II. Ara funeraria hallada junto al Pte. de los Franceses.

Por lo que se refiere a los restos romanos en zonas cercanas (fig. 13), debemos mencionar el hallazgo, a comienzos de siglo de un ara funeraria, a mano izquierda del Manzanares, al lado del Puente de los Franceses ${ }^{36}$,

36 El ara es de granito $(93 \times 36 \times 28 / 27)$ y presenta dos campos epigráficos superpuestos $(30 \times 33$ y 29x 33). Agradecemos al Centro CIL II la información bibliográfica sobre el epígrafe.

En relación a este ara funeraria son varias las menciones en la bibliografía desde que F. FITA la diese a conocer: FITA, F., «Lápidas romanas de Madrid», BRAH LVI (1910), p. 176:

Aemilia T(iti) l(iberta) Eutycia, ann(orum) [XX?]X. S(it) T(ibi) t(erra) l(evis).

Aemilius [T(iti) f(ilius)?] Etur[icus an]n(orum) VII. S(it) t(ibi) t(erra) I(evis).

Fuldio, F. Carpetania Romana, Madrid 1934, en la p. 135 describe la lápida romana, con una lectura y transcripción que nada tiene que ver con los realizados por $F$. Fita:

Aemilia t(ibi) I (iberta) Eutychia annorum (...?) X!

Sit tibi terra levis. Aemilius t(ibi) Eturius (an) $n$ (orum) VII. Sit tibi terra levis

CAmpo, E., El Museo Pontevedra, 25 (1971), en la p. 272 se presenta un espléndido dibujo del ara, en cuyo encabezado se lee: «En la carretera de El Pardo, cerca del Pte. de los Franceses».

EZquerRA, R., "Antigua epigrafía madrileña", Anales del Instituto de Estudios Madrileños XXV (1988), pp. 222-223, vuelve a los errores de Fuidio.

KNAPP, R.C., Latin Inscriptions from Central Spain (University of California Press), Berkeley, Los Angeles, Oxford 1992, no 183, pp. 162-163, lám. 15. El autor realiza una nueva lectura: 


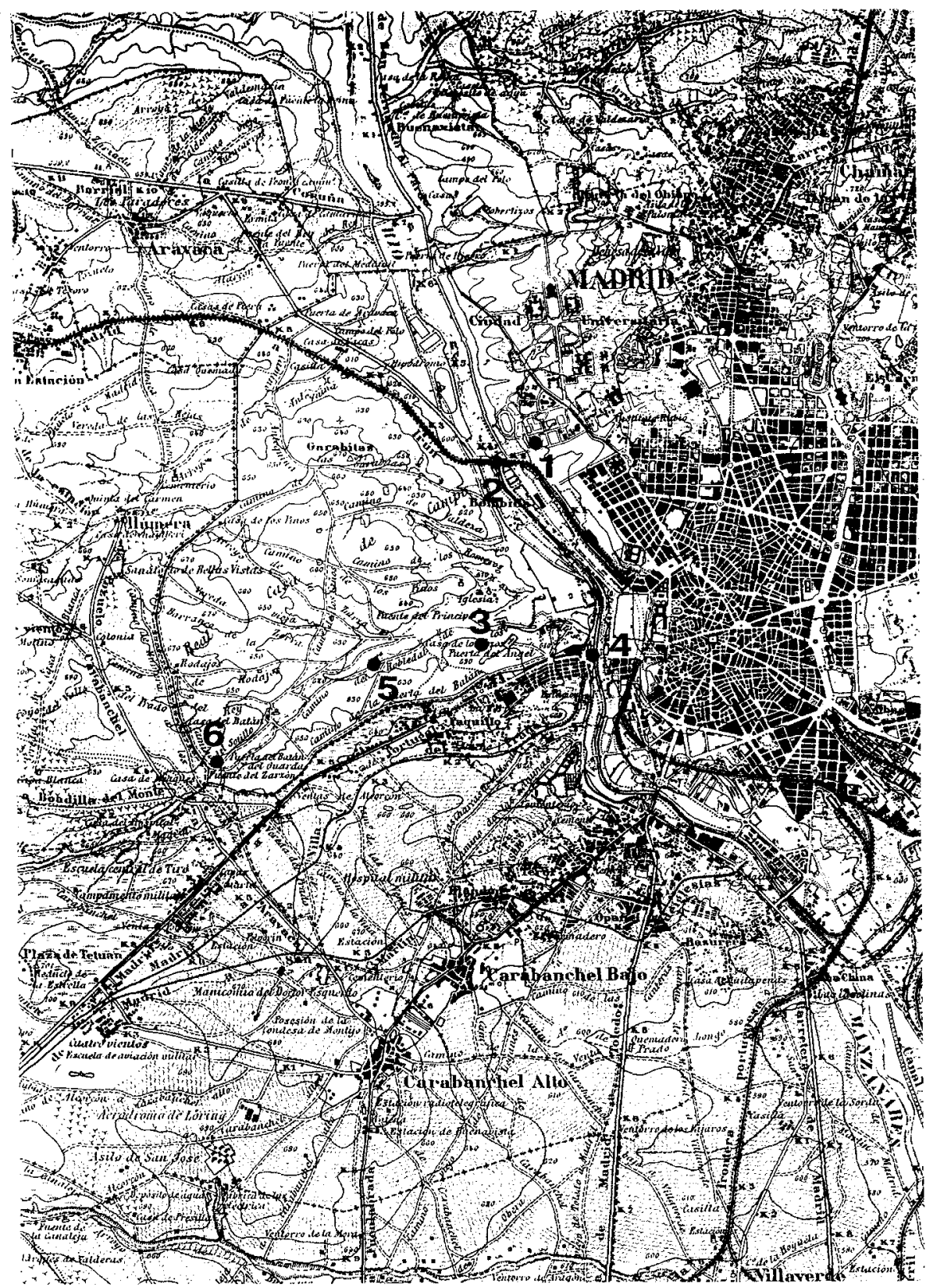

Figura 13. Situación de los restos romanos más cercanos: 1. Colegio Na Sra. de África.

2. Pte. de los Franceses. 3. Puerta del Ángel. 4. Puente de Segovia. 5. Camino de El Robledal. 
dedicada a Aemilia Heutycia y a un niño de 7 años, cuyo nombre sólo se conserva en parte. El ara apareció junto a otros restos cerámicos, tal y como recoge el testimonio de F. Fita de 1910:

«... porque en dicha huerta se han recogido diferentes monedas y algunos restos de cerámica romana, que son indicio de un cementerio, o columbario fúnebre, sito junto a la vía» ${ }^{37}$.

También J. Pérez de Barradas, en 1931-32 recoge este testimonio, siguiendo directamente a F. Fita, en la introducción que realiza al estudio de las villas de Villaverde Bajo ${ }^{38}$.

En 1934, F. Fuidio, en su conocida obra sobre la Carpetania romana, expresa textualmente el hallazgo: «... Cerca del sitio donde se encontró el canto rodado con inscrición latina, estudiada por D. Manuel GomezMoreno, Viloria junto a unos desmontes próximos al Puente de los Franceses encontró algunos trozos de terra sigillata» ${ }^{39}$.

El dato lo retoma J. Viloria, descubridor de estos restos romanos, según el anterior párrafo, en 1955, ya que incluye el Puente de los Franceses en su mapa de dispersión de yacimientos romanos, sin embargo en el texto no detalla los hallazgos ${ }^{40}$.

A partir de este momento y hasta décadas recientes, la existencia de un posible yacimiento en la citada zona no se menciona en ninguno de los estudios sobre la romanización en la región madrileña ${ }^{41}$. El Puente de los

\footnotetext{
a)

Aemili/a. Heuty/cia an(norum) / [-] s(it). t(ibi). t(erra). I(evis)

b)

[-]vilus / [-]VR / [-an(norum] . VII / s(it). t(ibi). t(erra). I(evis)

La lectura se mantiene en la revista Hispania Epigraphica 4 (1994), n 535, p. 199, fechando la inscripción por el tipo de letra en el s. II.

${ }_{37}$ FITA, F., op. cit., pp. 176.

38 Pérez de Batradas, J., op. cit. 1931-1932, p. 101

39 FUIDIO, F., op. cit., p. 86.

40 VILoRIA Rosado, J., "Yacimientos romanos de Madrid y sus alrededores", AEspA. XXVIII (1955), pp. 135-142. En concreto el yacimiento se numera con el 14 en el plano de dispersión de la p. 136.

41 ARCE, J., «La presencia romana en la provincia de Madrid», II Jornadas de estudios sobre la provincia de Madrid (Madrid, 25,26,27 y 28 de Noviembre de 1980), pp. 62-65. PrIEGO FERNÁNDEZ DEL CAMPO, M.C. et alii, "Prehistoria y Edad Antigua en el área de Madrid», en Madrid, Testimonios de su Historia hasta 1875, Madrid 1980, pp. 46-54. BALIL ILLANA, A., "La Romanización", en 130 años de arqueología madrileña (Real Academia de Bellas Artes de San Fernando. Febrero-Marzo 1987), Comunidad de Madrid 1987, pp. 136- 165. En la p. 156 sí hace referencia expresa a la inscripción funeraria hallada en el Puente de los Franceses. MÉndez MADARIAGA, A., "La región de Madrid en época romana», en Madrid del siglo IX al XI, (Madrid, octubre-noviembre 1990. Real Academia de Bellas Artes de San Fernando). Comunidad de Madrid 1990, pp. 15-29.
} 
Franceses vuelve a la bibliografía científica de la mano de E. de Carrera quien, en la crítica que realiza a la tábula Imperii Romani, correspondiente a la zona, sobre todo por la ausencia de la entrada de la voz Madrid, manifiesta en relación a las carencias de la TIR: «... y sobre todo la inscripción funeraria del Puente de los Franceses (lugar en el que se han producido recientemente nuevos hallazgos de época romana) que Fita supuso emplazada al borde de algún tramo de calzada que discurriese junto a la margen izquierda del río por ese punto» ${ }^{42}$.

La existencia de los nuevos hallazgos, producto de excavaciones científicas, como el que da a conocer en este artículo, ha llevado a considerar nuevamente el Puente de los Franceses como uno de los yacimientos romanos del término municipal madrileño y así aparece en distintos apartados del reciente catálogo sobre las villas romanas de Madrid ${ }^{43}$.

La cercanía geográfica entre los hallazgos de comienzos de siglo en la zona y el basurero que presentamos, nos lleva a considerar la posibilidad de que se trate de dos lugares relacionados con una villa: la zona de escombreras y la necrópolis, de la que se conserva la citada inscripción funeraria en los fondos del Museo Arqueológico Nacional de Madrid.

En relación a la posible ubicación de la villa, J.Sánchez Meseguer, tras analizar los vientos dominantes de Madrid, sugiere la posibilidad de que ésta se situe en la zona de altura similar y próxima a la cota de $600 \mathrm{me}$ tros, al noreste del basurero.

Por otro lado la idea expuesta por Fita de que la villa se encontrase cercana a una vía parece tener visos de realidad ya que en los estudios de G. Arias sobre la red viaria de la provincia de Madrid, se situa una vía de carácter secundario, denominada Vía del Esparto que, tras pasar por el centro de la ciudad procedente de Cartagena, saldría de la misma por el Puente de los Franceses y carretera de Castilla en dirección a El Escorial ${ }^{44}$.

El yacimiento tampoco se cita entre las prospecciones realizadas durante 1981. "Actividades del Instituto durante 1981. Sección Arqueológica del Museo Municipal», Estudios de Prehistoria y Arqueología Madrileñas 1 (1982), pp. 251-266. En el catálogo de yacimientos del río Manzanares, en el que se recogen aquellos que se conservan no se cita el hallado en el Pte. de los Franceses: Priego Fernández del Campo, M.C., Quero Castro, S., "Actividades de la sección arqueológica del Museo Municipal durante 1982", Estudios de Prehistoria y Arqueología Madrileñas 2(1983), pp. 288-310.

42 Carrera Hontana, E. DE, "La hoja K30 de la tábula Imperii Romani y Madrid», Estudios de Prehistoria y Arqueologia madrileñas 9 (1994), pp. 155-157, en concreto 156.

43 Las villas romanas de Madrid. Madrid en época romana, Madrid, 1995, pp. 22-23.

44 ARIAS, G., Repertorio de caminos de la Hispania romana, 1987, pp. 371-379 
Recientemente, con algunos cambios relativos a su trazado en el actual Madrid urbano, se vuelve a considerar este tramo de vía como un ramal secundario de la vía 25 del Itinerario de Antonino ${ }^{45}$. S. Palomero hace discurrir este tramo secundario de la vía 25 por el valle del Manzanares, considerando que serviría a todos los pequeños núcleos de tipo vicus-villae que se extiende por la zona y de los que el actual Madrid es uno de ellos ${ }^{46}$.

\section{HALLAZGOS ROMANOS EN ZONAS CERCANAS}

Efectivamente, a lo largo del río Manzanares han sido numerosos los hallazgos ${ }^{47}$, ya que la ribera del río fue, en época romana, lugar de asiento de numerosas villas, tanto agrícolas como de recreo, de entre ellas se debe destacar la hallada en el curso meridional del río, conocida como Villa de Villaverde que ha proporcionado numerosos hallazgos desde su descubrimiento en el año $1927^{48}$. Aunque ya un poco más alejada de la ribera del río, la denominada Villa de Carabanchel es también un importante núcleo de hábitat conocido desde mediados del siglo pasado ${ }^{49}$.

Especialmente numerosos son los hallazgos de la cercana Casa de Campo, si bien el único documentado arqueológicamente estaba situado cerca de la Puerta del Ángel, junto al arroyo Meaques y fue excavado en 1933 por Pérez de Barradas. Se hallaron gran cantidad de restos constructivos, teselas de mosaicos, pinturas, tejas, cerámicas, piedras de molino, y una piscina doble todo lo cual fue considerado como perteneciente a una villa ${ }^{50}$.

\footnotetext{
45 A. MENA, "La C1 entre Segóbriga y Madrid y otras sugerencias", El Miliario Extravagante, ño 24 (1989), pp. 5-9.

46 Álvarez González, Y., Palomero Plaza, S., «Las vías de comunicación en Madrid desde época romana hasta la caída del Reino de Toledo", en Madrid del siglo IX al XI, (Madrid, octubre-noviembre 1990. Real Academia de Bellas Artes de San Fernando). Comunidad de Madrid 1990, p. 53.

47 Véase el plano de distribución en la p. 23 en Las villas romanas de Madrid. Madrid en época romana, Madrid 1995.

48 La villa de Villaverde ha sido objeto de distintas publicaciones y aparece en la práctica totalidad de los artículos sobre el Madrid romano; un resumen actualizado en Las villas romanas de Madrid. Madrid en época romana, Madrid 1995, pp. 14-19.

49 El resumen más reciente sobre esta villa en JuAN HERNÁNDEZ, J. «En torno a la villa de Carabanchel: algunos materiales inéditos", Revista de la Biblioteca, Archivo y Museo del Ayuntamiento de Madrid 9-10 (1981), pp. 95-100.

50 Pérez de Barradas, J., "Excavaciones en la Casa de Campo, Madrid», Anuario de Prehistoria Madrileña IV-VI (1935), pp. 213-214. Esta zona ha sido identificada con Miaccum, mansio de la via 25 del Itinerario de Antonino: Tabula Imperii Romani. Hoja K.30: Madrid, Madrid 1993, pp. 150-151; identificación con la que otros autores están en desacuerdo; el estudio más reciente situa la citada mansio en las cercanías de El Escorial: Álvarez GonzÁlez, Y., Palomero PLAZA, S., op. cit., p. 52.
} 
Otros restos romanos, actualmente desaparecidos, se situaban en parajes tales como la Puerta del Batán, donde se hallaron abundantes fragmentos de terra sigillata, el Puente de Segovia, donde según Viloria se hallaron vestigios de un pequeño caserío romano y Camino del Robledal, donde fue hallada una fíbula con esmaltes del s. $1{ }^{51}{ }^{51}$. Lamentablemente los lugares donde se produjeron estos hallazgos han sido objeto de obras de urbanización y construcción del Ferrocarril Suburbano, por lo que estudiar los restos es prácticamente imposible. Aún así las labores de prospección llevadas acabo por el Instituto Arqueológico Municipal permitieron descubrir restos cerámicos en la zona El Batán ${ }^{52}$.

Con todo lo expuesto parece obligado concluir que la existencia de una villa en la zona del Puente los Franceses no es un hecho aislado, ya que la ribera del Manzanares debió ser asiento de numerosas villas rústicas, cuyos restos han desaparecido en la actualidad debido a la urbanización de la zona, pero han quedado en la memoria científica de numerosos investigadores que en la primera mitad del siglo dieron noticia de los hallazgos por ellos realizados.

A la importancia de sumar un nuevo hallazgo en Madrid y de poder relacionarlo con una villa, de cuya necrópolis se encontraron restos a comienzos de siglo, se añade el hecho de que uno de los pocos vestigios romanos excavados recientemente en la capital ${ }^{53}$ y que además aporta interesantes datos cronológicos y económicos para el análisis de la presencia romana en la zona. La aparición de los restos cerámicos estudiados implica un activo comercio en la zona centro de la Península, avalado en nuestro caso, por la existencia de una posible red viaria importante en zonas cercanas que sería el lugar de paso de una serie de productos comerciales que en este estudio se circunscriben a las especies cerámicas, algunas de las cuales, como las cerámicas vidriadas, procedían de otras provincias del Imperio.

\footnotetext{
51 FUIDIO, F., op. cit., pp. 86-87. VILORIA, J., op. cit. p. 135. Las villas romanas de Madrid. Madrid en época romana, Madrid 1995, p. 23. Solamente se cita como villa segura la hallada en la Pta. del Angel en 1933. TIR, Hoja: K.30, p. 84.

52 "Actividades del Instituto durante 1981. Sección Arqueológica del Museo Municipal «, Estudios de Prehistoria y Arqueología madrileñas 1 (1982),p. 260 y PRIEGo FeRNÁNDEZ deL CAMPO, M.C., Quero Castro, S., op. cit. 1983, pp. 290.

53 Son numerosos los hallazgos cerámicos de época romana en las excavaciones urbanas de Madrid, pero en la mayor parte de los casos se interpretan como traídos desde los areneros del Manzanares con los traslados de tierras; solamente en Tetuan y Ventas podría existir algún tipo de poblamiento: Las villas romanas de Madrid. Madrid en época romana, Madrid 1995, p. 23
} 
INVENTARIO DE MATERIALES

AF.94/2200

1. Frag. de borde de T.S.H., Drag. 15-17 (pasta 1).

2. Frag. de pared de T.S.H., Drag. 37, con decoración de círculos concéntricos segmentados (pasta 2) (fig. 4.2).

3. Frag. de pared de T.S.H., Drag. 37, con decoración de círculos sogueados y roseta de once pétalos en su interior (pasta 3).

4. Frag. de pared de T.S.H. lisa (pasta 3).

5. Frag. de pared de T.S.H. lisa (pasta 3 ).

6. Frag. de borde de T.S.H.A. (fig. 5.5).

7. Frag. de borde de T.S.H.A.

8. Frag. de fondo de T.S.H.A. Forma Hisp. 19. Pertenece al plato 2210.1 (fig. 5.3).

9. Frag. de borde de T.S.H.A., posiblemente de alguna variante de la forma 37 (carece de brillo metálico intenso) (fig. 5.4).

10. Frag. de cerámica de tradición indígena pintada con ajedrezado. Taller de Segobriga (fig. 6.5).

11. Frag. de cerámica pintada de tradición indígena.

12. Frag. de cerámica pintada de tradición indígena.

13. Frag. de borde de vaso de paredes finas, forma Mayet $\mathrm{XL}$, decorado con lúnulas de barbotina. Pasta gris muy depurada (fig. 6.2).

14. Frag. de borde de olla de cerámica oxidante, quemada en el interior. Tipo III.2 (fig. 9.5)

15. Frag. informe de cerámica reductora de pasta muy depurada.

\section{AF.94/2201}

1. Frag. de vaso de T.S.H. Drag. 35, con decoración de hojas de agua de barbotina en el borde. Presenta restos de sigillum, con parte de la letra $\mathrm{O}$ en el interior del fondo y grafito en el exterior (pasta 1) (fig. 3.2).

2. Frag. de vaso de T.S.H. Drag. 36, con decoración de hojas de agua de barbotina en el borde (pasta 1) (fig. 3.4).

\section{AF.94/2202}

1. Frag. de borde de vaso de paredes finas, forma Mayet $X L$, decorado con lúnulas de barbotina. Igual a 2200.13 (fig. 6.1). 
2. Frag. de fondo umbilicado de posible jarra o botella de cerámica de pasta anaranjada, con restos de decoración pintada de color rojo en la parte inferior (fig. 7.4).

3. Dos fragmentos de borde de olla de cerámica oxidante quemada. Tipo II.3. Es la misma pieza que 2204.13 (fig. 9.2).

4. Frag. de cazuela de cerámica oxidante, quemada en el exterior e interior, a excepción de la parte superior del labio (fig. 8.1).

5. Tres fragmentos de fondo plano de recipiente de cocina.

6. Frag. de borde de olla de cerámica oxidante, quemada en el labio. Tipo III.1 (fig. 9.4).

7. Frag. de cuenco o tapadera de cerámica oxidante quemada (fig. 11.2)

8. Frag. de cuenco de cerámica oxidante con el borde exterior oscurecido por efectos de la cocción. Misma pieza que 2204.7 (fig. 7.3).

9. Frag. de T.S.H. decorada, cuyo deterioro impide la identificación (pasta 2).

10. Frag. de borde de T.S.H. (pasta 2).

11. Frag. de borde de T.S.H., posible Ritt. 8 (pasta 2).

12. Frag. de pared de T.S.H. (pasta 2).

13. Frag. de pared de T.S.H. (pasta 1).

14. Frag. de pared de T.S.H. con decoración de círculos (pasta 2).

15. Frag. de pared de T.S.H. (pasta 4).

16- 30. Frags. informes de cerámica oxidante, de pastas depuradas.

31-37. Frags. informes de cerámica reductora de recipientes de cocina, con pastas muy groseras.

38. Frag. de imbrex.

\section{AF.94/2203}

1. Frag. de borde de T.S.H. Drag. 37 b, decorada con friso superior de ovas y metopas con motivos vegetales. (pasta 1) (fig. 3.5).

2. Frag. de borde de T.S.H. Drag. $37 \mathrm{~b}$, decorada con friso superior de ovas y metopas con cabeza de ciervo (pasta 1). (fig. 4.1).

3. Frag. de borde de T.S.H., Drag. 27. (pasta 2).

4. Frag. de borde de T.S.H. (pasta 2).

5. Frag. de fondo de T.S.H., con pie anular de sección rectangular. (pasta 1) (fig. 4.8).

6. Frag. de fondo de T.S.H. con sigillum, con escaso relieve, en el que puede leerse C OF. (pasta 2). 
7. Frag. de carena de T.S.H., Drag 15/17. (pasta 2).

8. Frag. de pared de T.S.H. con decoración de círculos sogueados separados por elementos verticales sin identificar. (pasta 2).

9. Frag. de T.S.H. lisa. (pasta 2).

10. Frag. de T.S.H. lisa (pasta 2).

11. Frag. de T.S.H., posible Drag. 27 (pasta 2).

12. Tres frags. de fondo de plato de T.S.H.A. Hisp. 19.

13. Frag. de vaso de paredes finas, variante de la forma Mayet $X L$ (fig. 6.3).

14. Frag. de borde de olla de cerámica oxidante quemada. Tipo III.2. Misma pieza que 2204.9-10.

15. Frag. de cuello de botella. Cerámica oxidante de pasta anaranjada con restos de engobe rojo en la panza (fig. 7.2).

16. Frag. de fondo de dolium (fig. 11.3).

17. Frag. de fondo umbilicado de posible jarra o botella de cerámica oxidante de pasta muy poco depurada y color ocre oscuro (fig. 7.5).

18. Frag. de asa con acanaladura central. Cerámica oxidante (fig. 7.6).

19. Frag. informe de mortero, con desgrasante muy grueso.

20-31. Frags. informes de cerámica oxidante.

32-44. Frags. informes de cerámica reductora de cocina.

45-59. Frags. de tejas.

AF.94/2204

1. Frag. de borde de T.S.H. Drag. 36. Es la misma pieza que 2002.1. (pasta 1) (fig. 3.4).

2. Frag. de borde de T.S.H. Drag. 35. Es la misma pieza que 2002.2. (pasta 1) (fig. 3.3).

3. Frag. de fondo de T.S.H. Drag. 37 decorada con círculos concéntricos. (pasta 2) (fig. 4.6).

4. Frag. de pared de T.S.H. Drag. 37 decorada con círculos concéntricos y restos de los cuartos traseros de un animal. (pasta 2) (fig. 4.5).

5. Frag. informe de T.S.H.A.

6. Frag. de fondo de plato de T.S.H.A. Forma Hisp. 19.

7. Frag. de cuenco de cerámica oxidante con el borde exterior oscurecido por efectos de la cocción. Es la misma pieza que 2202.8 (fig. 7.3). 
8. Frag. de borde de ollita de cerámica pintada de tradición indígena. Pasta ocre con filete negro cerca del borde exterior (fig. 6.6).

9. Tres frags. de olla de cerámica oxidante de cocina, con el labio quemado. Tipo III.2. Es la misma pieza que 2203.14 (fig. 10.6).

10. Frag. de borde de la olla 2203.14 y 2204.9 ; este fragmento no está quemado (fig. 10.6).

11. Frag. de borde de olla, totalmente quemado. Tipo III.2.

12. Frag. de borde de olla de cerámica oxidante quemada en el exterior. Tipo Ill.1 (fig. 9.3).

13. Frag. de borde de olla.Tipo II.3. Es la misma pieza que 2202.3 (fig. 9.2).

14-15. Frags. de ánfora.

16-22. Frags. de cerámica oxidante, de pastas depuradas.

23-46. Frags. de cerámica reductora, de recipientes de cocina.

47-54. Frags. de tejas.

AF. 94/2205

1. Frag. de fondo de T.S.H. Drag. 15/17. (pasta 1).

2. Frag. de pared de T.S.H. con decoración de hojas. (pasta 2).

3. Frag. de T.S.H. lisa (pasta 4).

4. Frag. de T.S.H. decorada. (pasta 2).

5. Frag. de T.S.H. lisa. (pasta 2).

6-9. Frags. de vasos de paredes finas de pasta gris muy depurada.

10. Frag. de mortero de cerámica oxidante, quemado. Es la misma pieza que 2207.12 (fig. 11.1).

11-15. Frags. informes de cerámica oxidante.

17-21. Frags. informes de cerámica reductora de cocina.

22-25. Frags. de tejas.

26-27. Dos clavos de hierro.

AF. $94 / 2206$

1. Frag. de borde de T.S.H. A. Hispa. 19.

2. Frag. de vaso de paredes finas con decoración de ruedecila.

3-4. Frags. de paredes finas de pasta gris. Es la misma pieza que 2205.6-9.

5. Frag. de borde de olla de cerámica oxidante quemada en el borde. Tipo III.2 Es la misma pieza que 2209.44 (fig. 9.6). 
6. Frag. de labio de olla. Tipo Il.2 (fig. 9.1).

7- 12. Frags. de cerámica oxidante.

13-51. Frags. de cerámica reductora de cocina.

52-56. Frags, de tejas.

57. Un clavo de hierro.

AF. 94/2207

1. Frag. de borde de T.S.H. Drag. 15/17. Misma pieza que 2209.1. (pasta 2) (fig. 3.1).

2. Frag. de carena de T.S.H. Drag. 15/17. Misma pieza que 2209.3. (pasta 1).

3. Frag. de pared de T.S.H. con decoración de círculos concéntricos segmentados. (pasta 2).

4. Frag. de pared de T.S.H. con decoración de círculos concéntricos segmentados. (pasta 2).

5-6. Frags. de T.S.H. lisa. (pasta 1).

7-8. Frags. de T.S.H. lisa. (pasta 2).

9. Frag. de T.S.H. decorada. (pasta 4).

10-11. Frags. de T.S.H. decorada con círculos. (pasta 2).

12. Frag. de mortero con restos de la vertedera. Es la misma pieza que 2205/10 (fig. 11.1).

13. Frag. de borde de olla de cerámica oxidante. Tipo III. Es la misma pieza que 2209.45 (fig. 10.1).

14. Frag. de borde de olla de cerámica oxidante quemada. Tipo I (fig. 8.3).

15. Frag. de fondo plano de cerámica reductora. Alisado exterior.

16. Frag. de borde de olla de cerámica reductora. Es la misma pieza que 2209.37-38. Tipo II.1 (fig. 8.4).

17-18. Frags. de cerámica oxidante.

19-78. Frags. de cerámica reductora.

79-96. Frags, de tejas.

\section{AF. 94/2208}

1. Frag. de la parte inferior de pondus.

2. Pondus, fragmentado en la parte superior (fig. 12.1).

3. Pondus, fragmentado en la parte superior. 
AF. 94/2209

1. Frag. de borde de T.S.H. Drag. 15-17. Es la misma pieza que 2007.1 (fig. 3.1).

2. Frag. de borde de T.S.H., posible Drag. 18. (pasta 4).

3. Frag. de fondo de T.S.H. Drag 15/17. Es la misma pieza que 2007.2.

4. Frag. de panza de T.S.H., posible Drag. 37, con decoración de círculos con rosetas, sobre los que se situan series de ángulos y bastones segmentados rectilíneos. (pasta 1) (fig. 4.4).

5. Frag. de T.S.H. decorada, posible Drag. 37. (pasta 2).

6. Frag. de T.S.H. decorada con círculos segmentados. (pasta 2).

7. Frag. de T.S.H. decorada con líneas ondulantes. (pasta 4).

8-11. Frags. de T.S.H. decorada. (pasta 2).

12. Frag. de T.S.H. lisa. (pasta 2).

13. Frag. de T.S.H. lisa. (pasta 1).

14-15. Frag. de T.S.H. lisa. (pasta 2).

16. Frag. de T.S.H. lisa. (pasta 1).

17. Frag. de T.S.H. lisa. (pasta 2).

18-19. Frag. de borde de plato de T.S.H.A., forma Hisp. 19 (fig. 5.1).

20. Frag. de plato de T.S.H.A., forma Hisp. 19 (fig. 5.2).

21. Frag. de fondo de plato de T.S.H.A., forma Hisp. 19. De la pieza $n^{\circ} 18-19$ o de la 20.

22. Frag. de borde de plato de T.S.H.A., forma Hisp. 19. De la pieza oㅜ 18-19 o de la 20.

23. Frag. de fondo de plato de T.S.H.A., forma Hisp. 19. De la pieza $n^{\circ} 18-19$ o de la 20.

24. Frag. de borde de plato de T.S.H.A., forma Hisp. 19. De la pieza oㅜ 18-19 o de la 20.

25. Frag. de fondo de plato de T.S.H.A., forma Hisp. 19. De la pieza $n^{\circ} 18-19$ o de la 20.

26. Frag. de borde de plato de T.S.H.A., forma Hisp. 19. De la pieza $n^{0} \mathbf{1 8 - 1 9}$ o de la 20.

27. Frag. de borde de plato de T.S.H.A., forma Hisp. 19. De la pieza $n^{0} 18-19$ o de la 20.

28. Frag. de fondo de plato de T.S.H.A., forma Hisp. 19. De la pieza $n^{\circ}=18-19$ o de la 20. 
29. Frag. de fondo de plato de T.S.H.A., forma Hisp. 19. De la pieza $n^{2}$ 18-19 o de la 20.

30. Frag. de borde de plato de T.S.H.A., forma Hisp. 19.

31-32. Frags. informes de cerámica de pasta gris muy depurada y con barniz negro.

33. Frag. de cerámica de pasta rojo ladrillo muy depurada y decorada con acanaladuras (fig. 7.7).

34. Frag. de botella de cerámica de pasta rojiza, muy depurada con posible alisamiento en el cuerpo y el borde quemado (fig. 7.1).

35. Frag. informe de cerámica pintada de tradición indígena, de pasta marrón y línea negra.

36. Frag. informe de cerámica pintada de tradición indígena, de pasta rojiza y línea negra.

37-38. Frags. de borde de olla de cerámica reductora. Es la misma pieza que 2207.16. Tipo Il.1 (fig. 8.4).

39. Frag. de borde de olla de cerámica oxidante quemada. Tipo III.2 (fig. 10.2).

40. Frag. de borde de olla de cerámica oxidante quemada. Tipo III.2 (fig. 10.3).

41. Frag. de borde de olla de cerámica oxidante quemada. Tipo III.2 (fig 10.4).

42. Frag. de borde de olla de cerámica reductora. Es la misma pieza que 2209.37-38.

43. Frag. de borde de olla de cerámica oxidante. Tipo I (fig. 8.2).

44. Frag. de borde de olla de cerámica oxidante quemada. Tipo III.2. Es la misma pieza que 2206.5.

45. Frag. de borde de olla de cerámica oxidante. Misma pieza que 2207.13. Tipo III.2 (fig. 10.1).

46-47. Frags. informes de ánforas.

48-153. Frags. informes y de tamaño muy pequeño de cerámica reductora.

154-166. Frags. de tejas.

AF. $94 / 2210$

1. Plato de T.S.H.A., forma Hisp. 19 (fig. 5.3).

AF. $94 / 2211$

1. Aguja de hueso (acus crinales). 
AF. $94 / 2212$

1. Pieza de hierro de forma semicircular.

AF. $94 / 2213$

1-2. Frags. informes de cerámica vidriada de color verde.

AF. 94/2214

1-2. Frag. de borde de T.S.H. Drag. 36, con decoración de hojas de agua a la barbotina. (pasta 2).

3. Frag. de fondo de T.S.H. con decoración de ruedecilla en el interior. Misma pieza que 2215.1. (pasta 4) (fig. 4.7).

4 y 6. Frags. del friso inferior de T.S.H., Drag. 37, con decoración de círculos sogueados. (pasta 2).

5, 7-9. Frags. de T.S.H., Drag. 37, con decoración metopada, de la que sólo se conservan las líneas ondulantes y motivo vertical sin identificar (pasta 2) (fig. 4.3).

10. Frag. de T.S.H. decorada con líneas ondulantes. (pasta 4).

11. Frag. de T.S.H., Drag. 37 decorada con círculos separados por motivos verticales. (pasta 2).

12. Frag. de T.S.H. decorada, correspondiente a la carena con baquetón interno de una Drag. 30. (pasta 2).

13. Frag. de T.S.H. decorada con círculos segmentados. (pasta 2).

14. Frag. de T.S.H. decorada con círculos segmentados. (pasta 2).

15. Frag. de T.S.H. decorada con ángulos o puntas de flecha. (pasta 2).

16. Frag. de T.S.H. decorada (pasta 2).

17. Frag. de T.S.H. decorada con círculos y motivo central indeterminado (pasta 2).

18. Frag. de T.S.H. decorada con círculos. (pasta 4).

19. Frag. de T.S.H., Drag. 27? (pasta 2).

20-35. Frags. de T.S.H. lisa y de tamaño muy pequeño. (pasta 2).

36-39. Frags. de T.S.H. lisa y de tamaño muy pequeño. (pasta 4).

40. Frag. de T.S.H.A., forma Hisp. 19. Es la misma pieza que 2209.20 (fig. $5.2)$.

41. Frag. de vaso de paredes finas, de pasta gris y decorado con ruedecilla.

42. Frag. de borde de cerámica oxidante, de pasta anaranjada y engobe rojo. Forma 18A de Abascal del taller de Segobriga (fig. 6.4). 
43. Frag. de cerámica oxidante con engobe rojo y decoración pintada

44-46. Frags. informes de de cerámica pintada de tradición indígena (fig. 6.7).

47-50. Frags. de cerámica oxidante de pastas muy depuradas, posiblemente pintadas de tradición indígena.

51. Frag. de la parte inferior de pico de lucerna.

52. Frag. de borde de olla de cerámica oxidante. Tipo III.2 (fig. 10.5).

53-141. Frags. informes de cerámica reductora de cocina

142-145. Frags. de tejas (fig. 12.2-3).

\section{AF.94/2215}

1. Frag. de fondo de T.S.H. decorado con ruedecilla en el interior y con grafito exterior. Misma pieza que 2214.3. En el exterior del fondo presenta la característica moldura hispánica (fig. 4.7).

2. Frag. de pared de T.S.H. decorado con círculos concéntricos, posible Drag 37. (pasta 2).

3-4. Frag. de pared de T.S.H. decorado con metopas. (pasta 2).

5. Frag. de pared de T.S.H. decorado. (pasta 2).

6. Frag. de T.S.H. (pasta 2).

7-9. Frags. de T.S.H. (pasta 2). 